\title{
Arquitetura hospitalar: a adequação do projeto na fase do estudo preliminar
}

\section{Hospital architecture: the adequacy of project preliminary study phase}

Eliete de Pinho Araujo ${ }^{1}$ Maritza Giacomazzi Dantas ${ }^{2}$
1 Arquiteta, professora do curso de Arquitetura e Urbanismo, FATECS, UniCEUB, orientadora PIBIC 2010, mestre pela FAU- UNB, doutora pela Escola Nacional de Saúde Pública - FIOCRUZ.E-mail: <eliete.araujo@uniceub.br>.

2 Estudante do curso de Arquitetura e Urbanismo, FATECS, UniCEUB. Projeto de Iniciação Científica - PIBIC 2010.

\section{Resumo}

O hospital, em seu conceito atual, é considerado uma "máquina de curar". Nesse sentido, a arquitetura hospitalar transformou-se em um "instrumento de cura" que deve se preocupar com a criação de ambientes que contribuam com o processo de melhora dos pacientes. Entretanto, a arquitetura deve andar em paralelo com os avanços tecnológicos da medicina, mantendo a racionalidade do projeto sem que haja a perda da humanização do espaço. Este estudo pretende mostrar que o planejamento adequado do projeto arquitetônico de um ambiente de saúde, além de conciliar bem-estar à tecnologia, contribui para a harmonização funcional do Estabelecimento Assistencial de Saúde - EAS, premedita problemas provenientes do pós-ocupacional e evita problemas na fase do estudo preliminar e do desenvolvimento do projeto básico. O tema e os objetivos deste estudo devem destacar que um projeto planejado de forma apropriada garante a concordância estética e funcional e minimiza a problemática usual do EAS. Foram realizadas pesquisas bibliográficas, análise das obras de arquitetos e visitas aos EAS, a fim de reconhecer possíveis problemas. Em seguida, foram analisados os dados obtidos na pesquisa e ainda propostas alterações em relação à morfologia. Os resultados vão fornecer uma contribuição teórica e prática para profissionais e estudantes na área de arquitetura hospitalar.

Palavras-chave: Saúde. Estudo preliminar. Arquitetura hospitalar.

\section{Abstract}

The hospital, in its present concept, is considered a "healing machine". In this sense, the hospital architecture has become a "healing tool" and should be concerned with creating environments that contribute to the process of improvement of patients. However, the architecture should go in parallel with the technological advances of medicine, keeping the rationality of the project without the loss of humanization of space. This study aims to show that proper planning of the architectural design of a health environment, and combines well-being technology, to help harmonize functional Establishment of Health Care - EHC, premeditates problems from the post-occupational and avoid problems during the preliminary study and developing the basic design. The theme and objectives of this study should point out that a properly planned project ensures compliance aesthetic and functional problems and minimizes the usual EHC. Were carried out literature search, review the work of architects and visits to EHC in order to recognize potential problems. After we analyzed the data obtained in the research and proposed changes to the 
morphology. The results will provide a theoretical and practical contribution for professionals and students in the area of hospital architecture.

Keywords: Health. Preliminary study. Hospital architecture.

\section{Introdução}

O tema "Arquitetura Hospitalar - a adequação do projeto na fase de estudo preliminar" consiste no estudo da importância de um bom planejamento de um projeto arquitetônico no Estabelecimento Assistencial de Saúde (EAS), na sua fase de estudo preliminar e na concepção do projeto básico. O Hospital Regional do Paranoá ( $\mathrm{HRPa}$ ) é um Estabelecimento Assistencial de Saúde da Secretaria de Saúde do Distrito Federal e foi escolhido como estudo de caso para esta pesquisa (Figura 1).

Figura 1: Foto aérea via satélite da locação do Hospital do Paranoá (HRPa)

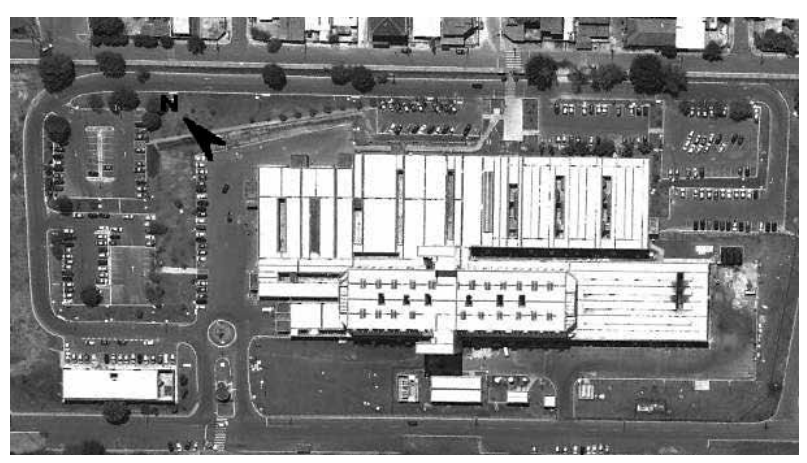

Fonte:<http://www.saude.df.gov.br/003/00301009.asp?ttCD_CH $\mathrm{AVE}=26233$

A construção do hospital iniciou-se em 2000 e se concluiu em 2003. Possui uma área útil de $23.000 \mathrm{~m}^{2} \mathrm{e}$ 200 leitos.

Segundo dados da Secretaria de Saúde do Distrito Federal, o HRPa atende, mensalmente, a 2.250 pacientes nos ambulatórios e a 10.750 na emergência.

Como objetivo geral, este estudo buscou enumerar problemas usuais encontrados no ambiente hospitalar provenientes de um projeto arquitetônico com falhas na sua concepção preliminar e como objetivos específicos, destacar a utilização de recursos naturais adequados ao meio ambiente; a preocupação com a humanização do projeto, sem que haja o afastamento da racionalidade; a predição de possíveis modificações no projeto inicial-

\section{Problemática e justificativa}

O projeto de um ambiente de saúde deve se preocupar com a segurança e o bem-estar de seus funcionários, administradores e particularmente dos pacientes. Tal ambiente está diretamente ligado à saúde do homem e, portanto, deve haver eficácia no desenvolvimento do projeto arquitetônico, visando ao cumprimento das normas que regulamentam o uso dessas edificações.

A arquitetura hospitalar deve estar a serviço das pessoas, dando estima à humanização do espaço e, paralelamente, estar aliada aos avanços tecnológicos da medicina, prevendo possíveis modificações no projeto.

Este estudo pretende mostrar que são diversos os problemas estruturais, de instalações, de conforto ambiental e de acessibilidade em hospitais, que poderiam ser evitados durante o desenvolvimento do estudo preliminar.

\subsection{Revisão bibliográfica / fundamentação teórica}

É essencial que o arquiteto, ao desenvolver um projeto, preocupe-se com a legislação e a normatização vigentes, específicas de um ambiente hospitalar, pois o planejamento arquitetônico visa à qualidade e ao bem-estar de seus usuários, levando-se em conta, então, uma revisão nas normas da ANVISA, Ministério da Saúde e normas da ABNT relativas a hospitais, incluindo a acessibilidade, o conforto ambiental, o layout, ou seja, identificando a adequabilidade da arquitetura voltada para a humanização.

As normas que fundamentaram este trabalho de pesquisa foram a RDC 50 - 2002/Ministério da Saúde, que é a mais importante para a arquitetura, pois estabelece informações para planejamento, programação, elaboração e avaliação de projetos físicos de estabelecimentos assistenciais de saúde. A NBR 9.050 - 2004/ABNT, que regulamenta critérios e parâmetros técnicos para a adaptação de espaços, mobiliário e edificações às condições de acessibilidade e a NBR 7.256 - 2005/ABNT, que estabelece critérios de tratamento de ar em estabelecimentos assistenciais de saúde de acordo com os conceitos, resoluções e regulamentações técnicas estipuladas pela ANVISA.

Os autores de referência na arquitetura hospitalar que embasaram o trabalho, são os citados a seguir.

Na década de 1990, Campos (1944), em "História e evolução dos hospitais", traça um panorama sobre a 
evolução da medicina como ciência, bem como sobre o surgimento do hospital como instituição até seu conceito atual; Foucault (1979), em "Microfísica do poder", mostra a relação entre o "saber" e o "poder" na sociedade capitalista atual, cujo interesse é produzir "verdades" como forma de dominação do homem. A instituição hospitalar é analisada como um local destinado à exclusão de minorias, ao contrário de sua função primordial de assistir e curar os que a procuram; Karman (1995),em "Manutenção incorporada à arquitetura hospitalar", defende que a arquitetura deve ser preditiva, pondo-se à disposição das transformações sofridas em um EAS no pós-ocupacional; Fiorentini (1995), em "Arquitetura na prevenção da infecção hospitalar”, destaca de que maneira a arquitetura infecto-preditiva contribui no combate à infecção hospitalar; a obra corresponde a uma série de textos publicados pelo Ministério da Saúde que analisam critérios para projetos físicos de EAS. Esse, especificamente, trata de como a arquitetura, por meio de soluções projetuais, transforma ambientes de saúde em locais íntegros e assépticos, auxiliando dessa forma na prevenção da infecção hospitalar. Santos e Bursztyn (1996), afirmam que "profissionais e usuários de edificações onde são desenvolvidas atividades de atenção à saúde costumam registrar em suas memórias experiências que gostariam de modificar. As reflexões que ficam assinaladas são referências para a construção de novos modelos de arquitetura”.

$\mathrm{Na}$ década seguinte (2000), houve destaque para os autores a seguir:

Toledo (2002), em "Feitos para curar", faz um histórico do estabelecimento assistencial de saúde no Brasil e no mundo e suas transformações; destaca normas, tipologias e exemplifica seu discurso, de maneira crítica, com projetos já existentes, além de discutir a função que a arquitetura desempenha no processo de cura dos pacientes.

Limeira (2006), em "Arquitetura e integralidade em saúde: uma análise do sistema normativo para projetos de estabelecimentos assistenciais de saúde", faz uma análise crítica da normatização em saúde, com destaque para a RDC 50 - 2002, atentando para o problema de legitimidade e adequação dela às necessidades das pessoas.

Sampaio (2006), em "Arquitetura hospitalar: projetos ambientalmente sustentáveis, conforto e qualidade", analisa os conceitos de sustentabilidade e conforto ambiental e destaca a preocupação que projetos hospitala- res devem ter, desde o início, com a adequação ao local que estão inseridos e com o aproveitamento dos recursos naturais disponíveis. Defende como a arquitetura, aliada a soluções simples que seguem princípios de sustentabilidade e de conforto ambiental produz ambientes hospitalares de qualidade, melhorando o desempenho energético da edificação, assim como o bem-estar de seus usuários.

Westphal (2007), em "A linguagem da arquitetura hospitalar de João Filgueiras Lima", descreve e analisa os elementos e características que conferem identidade e diferenciam as obras do arquiteto João Filgueiras, utilizando como objeto de estudo os hospitais da Rede Sarah Kubitschek.

Araújo (2008), em "Avaliação crítica de ambientes em estabelecimentos assistenciais de saúde", analisa a problemática encontrada nos EAS relativa à qualidade do ar pelo sistema de ar condicionado em ambientes climatizados, o descarte dos produtos químicos oriundos das processadoras de filmes radiográficos no meio ambiente, envolvendo a salubridade das câmaras escuras, e analisa também um dos fatores que contribuem para a sustentabilidade, propondo a implantação do reuso da água proveniente da Estação de Tratamento de Esgoto.

\subsection{Metodologia}

Foi realizada pesquisa bibliográfica sobre o histórico do estabelecimento assistencial de saúde e da evolução da arquitetura hospitalar com o intuito de situar-se a respeito do assunto e suas problemáticas.

Concluída essa etapa, foram estudadas obras do arquiteto João Filgueiras Lima, destacando suas características arquitetônicas com o objetivo de identificar os diferenciais de seus projetos hospitalares.

Como trabalho de campo, foram realizadas visitas ao Hospital Regional do Paranoá, a fim de reconhecer a problemática descrita na literatura e levantar possíveis problemas que não foram detectados durante o estudo inicial dos projetos, de maneira a poder compreender a importância de se priorizar o conforto ambiental, a acessibilidade, a adequação à topografia e ao modus operandi durante o desenvolvimento do estudo preliminar.

Por fim, foram propostas alterações em relação à morfologia, de acordo com a análise dos dados encontrados; e, como retorno, apresentam-se: 
- Proposta criativa e inovadora;

- Qualidade ambiental;

- Contribuição para os projetistas da área de arquitetura e urbanismo;

- Contribuição para os profissionais envolvidos com o tema; e

- Contribuição para a saúde pública.

\subsection{Limitações da pesquisa}

Um estabelecimento assistencial de saúde estrutura-se basicamente em oito unidades: Atendimento em regime ambulatorial e de hospital-dia, Atendimento imediato, Atendimento em regime de internação, Apoio ao diagnóstico e terapia; Apoio técnico, ensino e pesquisa; Apoio administrativo; e Apoio logístico.

Neste trabalho, foram estudadas apenas as quatro primeiras unidades por lidarem diretamente com a saúde e integridade dos usuários e funcionários. A pesquisa analisou como o projeto arquitetônico influencia positiva ou negativamente na boa execução das funções que devem ser desempenhadas em cada uma dessas áreas.

\section{Desenvolvimento da pesquisa}

\subsection{Histórico}

A palavra hospital vem do latim hospitalis e significa "ser hospitaleiro, acolhedor", adjetivo derivado de hospes, que se refere àquele que dá hospedagem porque, antigamente, peregrinos e viajantes eram recebidos nessas casas de assistência. Entretanto, o termo hospital, com sua noção atual, encaixa-se melhor às acepções nosocomium e nosodochium, ambas de origem grega, que significam, respectivamente, "tratar os doentes" e "receber os doentes".

Apesar de a cultura cristã ter impulsionado os serviços de assistências aos necessitados sob diversas maneiras, a origem do hospital é anterior a ela. O príncipe Siddhartha Gautama, fundador do budismo, cuja época estima-se cerca de 563 a.C e 483 a.C, foi responsável pela construção de instituições hospitalares e, junto a elas, nomeava a cada dez cidades um médico responsável por atendê-las.

$\mathrm{Na}$ Grécia, os primeiros locais destinados ao atendimento de enfermos foram templos dedicados ao Escapulário (nome latino de Asclépio - o deus grego da medicina), habilidoso médico que exerceu tal profissão durante a Guerra de Troia. Nesses templos, a serpente representava o símbolo da divindade e o poder da cura, portanto, era sagrada, e acreditava-se que era dotada de magia.

Campos (1944, p.17) relata:

[...] os templos primavam pelo ambiente favorável à cura dos doentes. Erigiam-se nas colinas ou nas fraldas das montanhas abrigadas contra os ventos maléficos. Eram localizados ao lado das florestas e de uma fonte de águas minerais, de termas ou, pelo menos, de água puríssima. Consistiam de uma cobertura assente sobre colunas dóricas. Cada um destes santuários tinha um altar. Os serviços eram ministrados por sacerdotes (médicos). As práticas eram impregnadas de misticismo e superstição.

Nos primórdios e até mesmo após o surgimento do Cristianismo, as práticas da medicina e a religiosa se fundiam. $\mathrm{O} 4^{\circ}$ concílio de Cartagena ordenava que os hospitais fossem edificados ao lado das igrejas, assim como no Islamismo, eles surgiam junto às mesquitas.

No Renascimento, sob influência do Humanismo, os hospitais foram adquirindo caráter municipal e o progresso científico foi aprimorando, naturalmente, essas edificações.

No século XVIII, graças aos avanços da medicina, a enfermidade passa a ser reconhecida como fato patológico.

Com o surgimento desse conceito, as questões de ordem funcional e espacial assumem nova importância, estimulando o desenvolvimento dos primeiros processos projetuais dedicados às edificações hospitalares (TOLEDO, 2002).

A partir daí, as questões espaciais e sanitárias das edificações hospitalares assumem extrema importância, tornando-se, inclusive, objeto de estudo para estudiosos como Pasteur, cientista francês que desenvolveu pesquisas sobre contaminação por meio de micro-organismos, e Tenon, cirurgião francês que publicou o Mémoire sur les hôpitaux de Paris, que possuía descrições detalhadas sobre hospitais na França. Formou-se então, o conceito de hospital terapêutico: um instrumento destinado a curar (TOLEDO, 2002).

\subsection{Arquitetura hospitalar}

Considera-se que nenhuma teoria médica por si mesma é suficiente para definir um programa 
hospitalar. Além disso, nenhum plano arquitetônico abstrato pode dar a fórmula do bom hospital. Este é um objeto complexo de que se conhece mal os efeitos e as consequências, que age sobre as doenças e é capaz de agravá-las, multiplicálas ou atenuá-las. Somente um inquérito empírico sobre esse novo objeto ou esse objeto interrogado e isolado de maneira nova - o hospital - será capaz de dar idéia de um novo programa de construção dos hospitais. O hospital deixa de ser uma simples figura arquitetônica. Ele agora faz parte de um fato médico-hospitalar que se deve estudar como são estudados os climas, as doenças, etc." (FOUCAULT, 1979, p.58).

De nada adianta discorrer a respeito da arquitetura hospitalar sem ao menos ponderar sobre a evolução do edifício hospitalar, histórico que vem paralelo ao surgimento do hospital como instituição, ou seja, sob um ponto de vista específico que mais interessa aos profissionais ou aos estudiosos da área de Arquitetura.

Segundo Campos (1944), o credo de que a enfermidade era castigo divino esteve presente em diversas culturas". Os hospitais eram raramente frequentados por médicos, tendo suas consultas marcadas na residência do enfermo. Iam para o hospital apenas os pobres, os portadores de doenças contagiosas e as pessoas que já estavam para morrer. A partir do momento que a doença passa a ser reconhecida como fator patológico, surge uma preocupação com o processo projetual do edifício hospitalar.

$\mathrm{Na}$ Idade Média, surge, mesmo que timidamente, a preocupação com a salubridade desses ambientes. Três tipologias básicas eram comumente adotadas pelos hospitais cristãos, visando à renovação de ar e uso da luz natural; basilical, com naves abobodadas sustentadas por colunas (2); palaciano, com forma retangular ou quadrada composto por um ou dois pátios circundados por acomodação de enfermos (3); e cruciforme, derivado do palaciano, entretanto com as alas se cruzando, formando um pátio central (4) (Figura 2). Essa última tipologia variava também nos formatos "U”, "L" ou “T”.

Figura 2: Desenhos esquemáticos de análises tipológicas da evolução edifício hospitalar (formatos U, L e T)

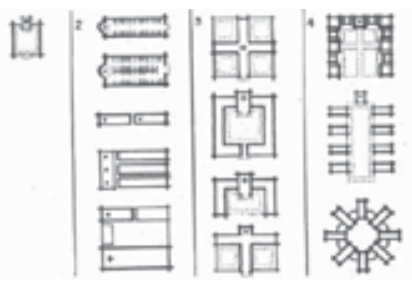

Fonte: TOLEDO, 2002. Feitos para curar.
A questão do edifício hospitalar foi posta em cheque posteriormente à proposta de reforma do Hôtel-Dieu (Figura 03), o maior hospital da França, parcialmente destruído em 1772 após um incêndio (LIMEIRA, 2006).

Figura 3: Proposta de reforma do Hôtel-Dieu do arquiteto Bernard Poyet - fachadas e planta de locação.

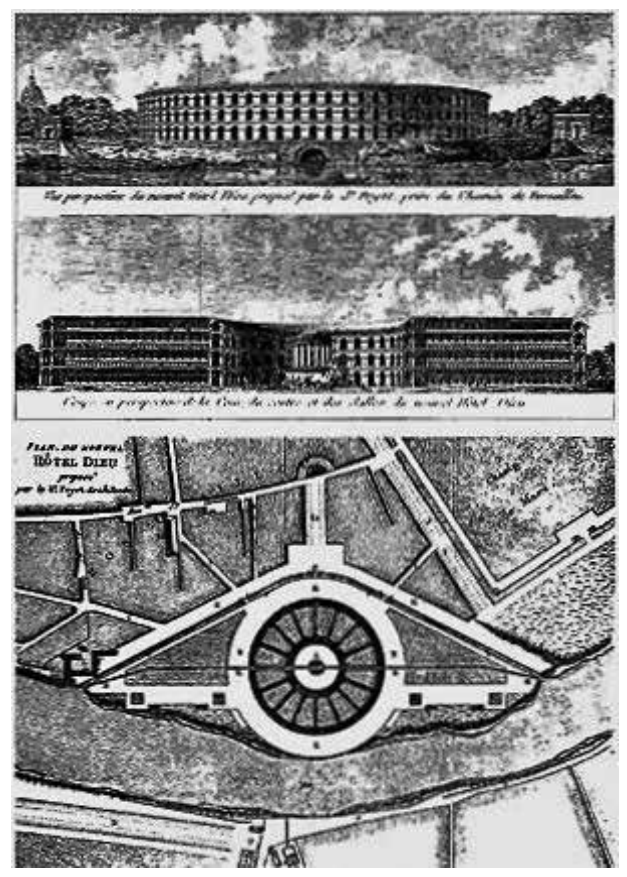

Fonte: SAMPAIO, 2005. Arquitetura hospitalar: projetos ambientalmente sustentáveis, conforto e qualidade.

Convocou-se a Academia de Ciências, formada por grandes nomes como Lassone, Daubeton, Bailly, Lavoisier, Laplace, Coulomb, D’Arcet e Tenon, para opinar sobre os projetos de reconstrução. Em 1775, Tenon percorreu diversas instituições de saúde pela Europa para definir quais são as condições de funcionamento dos hospitais.

Os resultados de seus estudos revelaram precariedades nas unidades estudadas, destacando-se as relações entre procedimentos médicos e de enfermagem, a taxa de mortalidade entre os pacientes e as características espaciais dessas edificações. A partir disso, Tenon escreveu o Mémoire sur les hôpitaux, um programa voltado para o projeto do edifício hospitalar, baseado nos pontos fortes e falhas dos locais visitados (TOLEDO, 2002).

Deve-se destacar também o surgimento do conceito hospital terapêutico, muito difundido por Foucault em meados do século XVIII, considerado a postulação base para a origem do conceito do hospital contemporâneo. A instituição de saúde perde seu caráter de exclusão 
social e ganha o título de "máquina de curar". Foucault, em Microfísica do Poder (1979, p. 63), destaca:

[...] o hospital é um meio de intervenção sobre o doente. A arquitetura do hospital deve ser fator e instrumento de cura. O hospital-exclusão, onde se rejeitam os doentes para a morte, não deve mais existir. A arquitetura hospitalar é um instrumento de cura de mesmo estatuto que um regime alimentar, uma sangria ou um gesto médico. O espaço hospitalar é medicalizado em sua função e em seus efeitos. - Esta é a primeira característica da transformação do hospital no final do século XVIII [...].

No século XIX, com o domínio da tecnologia do concreto armado e o advento do elevador, adotou-se a tipologia "monobloco vertical" que, segundo Toledo (2002, p.9):

[...] permitia, ainda, significativas economias no que se refere à construção do edifício hospitalar e sua posterior operação, na medida em que não apenas racionalizava os sistemas de infra-estrutura, distribuição de alimentos, roupas etc., como reunia, em unidades funcionais comuns, os serviços de esterilização, lavagem de roupa e nutrição que anteriormente eram localizados em cada um dos pavilhões. A partir dessa mudança, surgiu a concepção do "hospital arranha-céu.

O autor afirma ainda que o conceito de "máquina de curar" ainda permanece presente. A arquitetura hospitalar atual preocupa-se com o bem estar de seus usuários e da equipe de trabalho. A integração com o local, adequação ao clima, economia energética e preservação do meio ambiente, iluminação adequada, funcionalidade de espaços, satisfação das necessidades tecnológicas da medicina e o cumprimento das normas tornaram-se quesi- tos básicos que devem ser seguidos ao se desenvolver um projeto de edifício hospitalar nos dias atuais.

\subsection{João Filgueiras Lima: uma nova leitura do edifício hospitalar}

De linguagem arquitetônica ímpar, os projetos do arquiteto João Filgueiras Lima, mais conhecido como Lelé, são mundialmente conhecidos por suas soluções criativas.

Responsável pelas obras da Rede Sarah de Hospitais do Aparelho Locomotor, o autor utiliza elementos recorrentes em seus projetos, entretanto, adapta cada um deles ao programa de necessidades dado, aos materiais disponíveis no local e ao sítio. Outra característica de extrema importância encontrada na arquitetura de Lelé é sua preocupação em utilizar recursos naturais para maximizar o conforto ambiental; João Filgueiras claramente utiliza em seus projetos o conceito de hospital como "máquina de cura". O emprego de Sheds, muito recorrente nos hospitais da Rede Sarah Kubitschek, por exemplo, permite iluminação zenital e ventilação natural, além de tornar-se um elemento compositivo de forma das suas edificações.

Os hospitais da Rede Sarah, mesmo que diferentes na forma, precisam respeitar os seus modos próprios de funcionamento. $\mathrm{O}$ arquiteto identifica as unidades funcionais que compõem o programa, maneja o posicionamento dos setores de acordo com um eixo ordenador, o que facilita a permeabilidade ao longo da edificação, evitando grandes áreas de isolamento e integração entre as unidades e o todo (Figura 04). 
Figura 4: Distribuição funcional ao longo do eixo ordenador no Hospital Sarah Lago Norte - planta baixa, s/ escala.

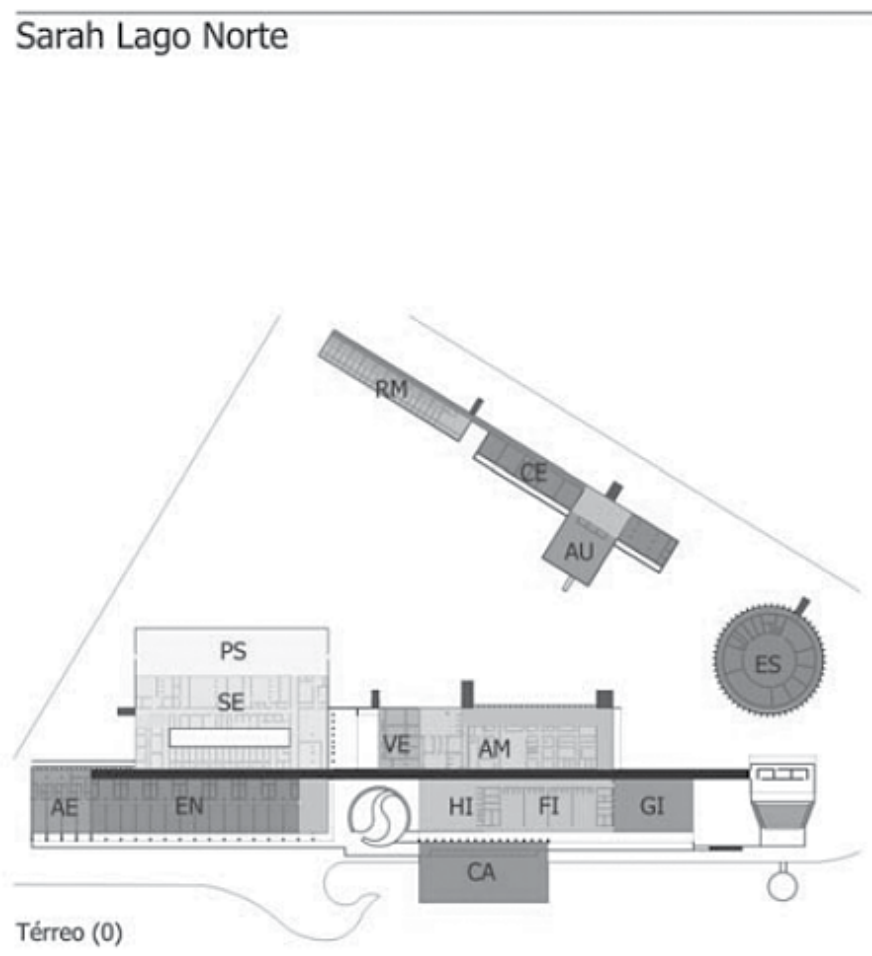

Legenda Unidades Funcionais:

AU - Auditório
CE - Centro de Estudos
RM - Residência Médica
ES - Escola
AM - Ambulatório
RA - Radiologia
OR - Ortopedia
AD - Administração do
Ambulatório
LA - Laboratório
AR - Arquivo Médico
CC - Centro Cirúrgico
IE - 10 estágio
IA - Internação e Alta
VE - Vestiário
EN - Enfermaria
AE - Apartamentos
FI - Fisioterapia
HI - Hidroterapia
GI - Ginásio Esportivo
CA - Cais
PS - Pátio de Serviço
SE - Serviços (cozinha,
lavanderia e refeitório)
AD - Administração
AL - Almoxarifado
CM - Central de Materiais

Fonte: WESTPHAL, 2007. A linguagem da arquitetura hospitalar de João Filgueiras Lima.

Os hospitais da Rede Sarah são compostos de contrastes: formas curvas com linhas retas e estáticas; o cinza do cimento com cores primárias; os fechamentos em contraposição aos elementos vazados. O conjunto dessa linguagem resulta na "máquina de curar" que Foucault conceituou: tratar da saúde física em um ambiente que valoriza a saúde mental de seus usuários, privilegiando conforto e bem estar.

João Filgueiras Lima consegue sincronizar o programa arquitetônico do hospital, seguindo suas exigências funcionais, criando verdadeiras obras de arte que são exemplo não apenas na sua beleza, mas na genialidade da composição do todo.

\section{Diagnóstico}

Segundo a norma da Agência de Vigilância Sanitária (ANVISA), a RDC 50/2002, um EAS possui, basicamente, oito unidades que o diferencia como Hospital-dia (Figura 05). Entretanto, não há a necessidade de haver todas essas unidades para caracterizá-lo como tal. Por exemplo, um hospital que se destaca devido a uma especialidade médica leva a atribuição de EAS e está sujeito, assim como estabelecimentos que possuem todas as áreas explicitadas, ao seguimento de todas as leis para eles designadas. 
Figura 05: Esquema das áreas de um EAS especificada na norma RDC 50/2002 da Anvisa.

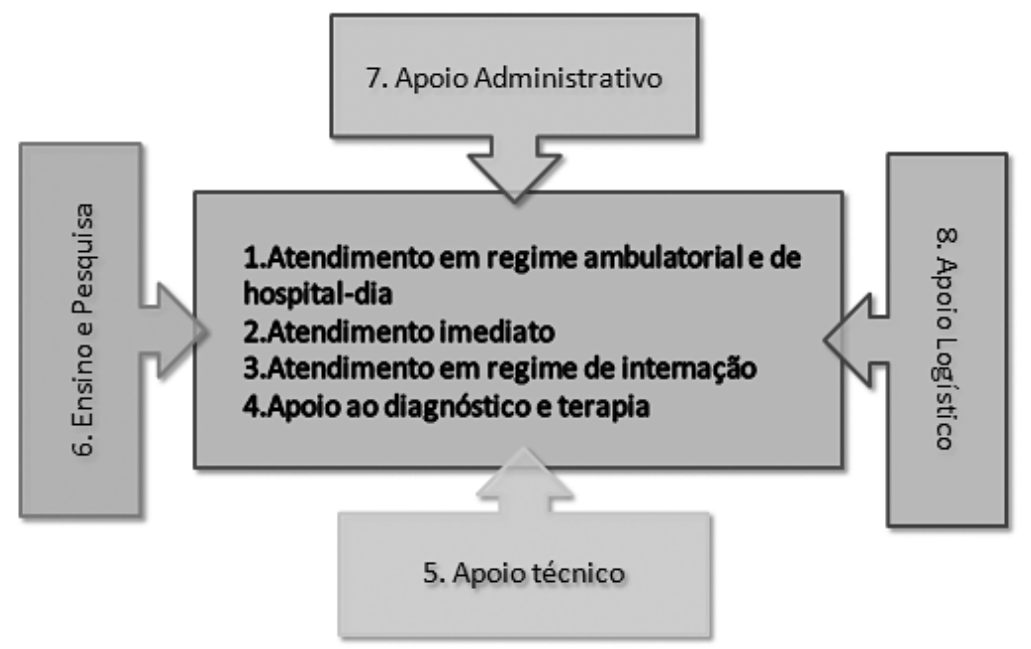

Fonte: Acervo pessoal

O HRPa possui tipologia pavilhonar dividida em blocos de, no máximo, dois pavimentos, combinada com monobloco vertical, esta última com seis pavimentos, utilizada no bloco de internação do HRPa (Figura 06).

Figura 06: Foto do HRPa

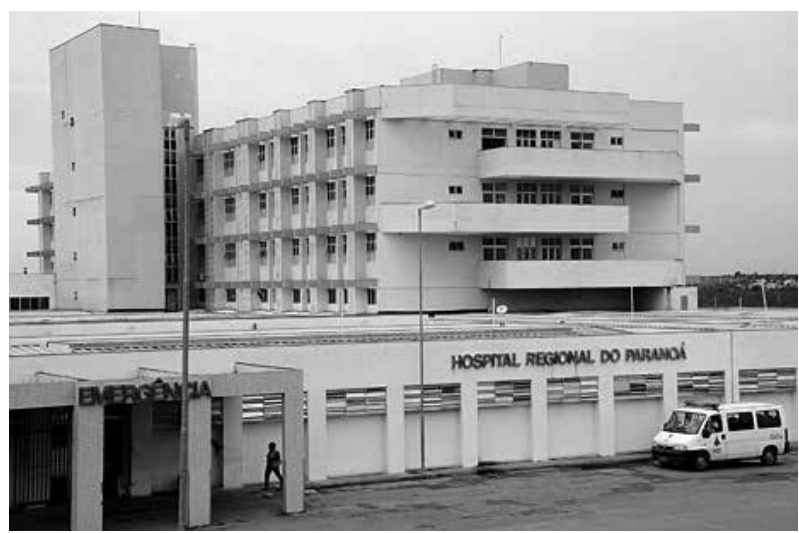

Fonte: <http://www.saude.df.gov.br/003/00301009.asp?ttCD_ $\mathrm{CHAVE}=26233>$

Os cinco blocos, nomeados das letras A a E, estão divididos da seguinte maneira (Figura 07 e Tabela 1):

- Bloco A: Unidade de Emergência, Setor de Diagnóstico, Anatomia Patológica e Ortopedia;
- Bloco B: Laboratório de Patologia Clínica, Radiologia, Ecografia e Unidade Transfusional;

- Bloco C: Ambulatório (consultórios) e Administração;

- Bloco D (subsolo): Casa das Máquinas e Reservatório Inferior;

Térreo: Central de Material de Esterilização, Centro Cirúrgico, Centro Obstétrico e UTI;

1. Pavimento: Bloco Técnico;

2. ${ }^{\circ}$ Pavimento: Internação, Auditório e Biblioteca;

3. Pavimento: Internação Obstétrica, Neonatal e Pediátrica;

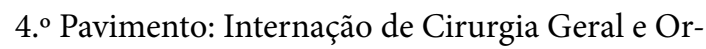
topédica;

5. Pavimento: Casa da Máquina e Reservatório Superior;

- Bloco E: Serviços Gerais e Refeitório;

- Bloco do Centro de Atenção Psicossocial (CAPS);

- Depósito de Inflamáveis: Grupo Gerador, Subestação e Central de Gases. 
Figura 07: Esquema de distribuição de áreas do HRPa - planta de locação, s/ escala.

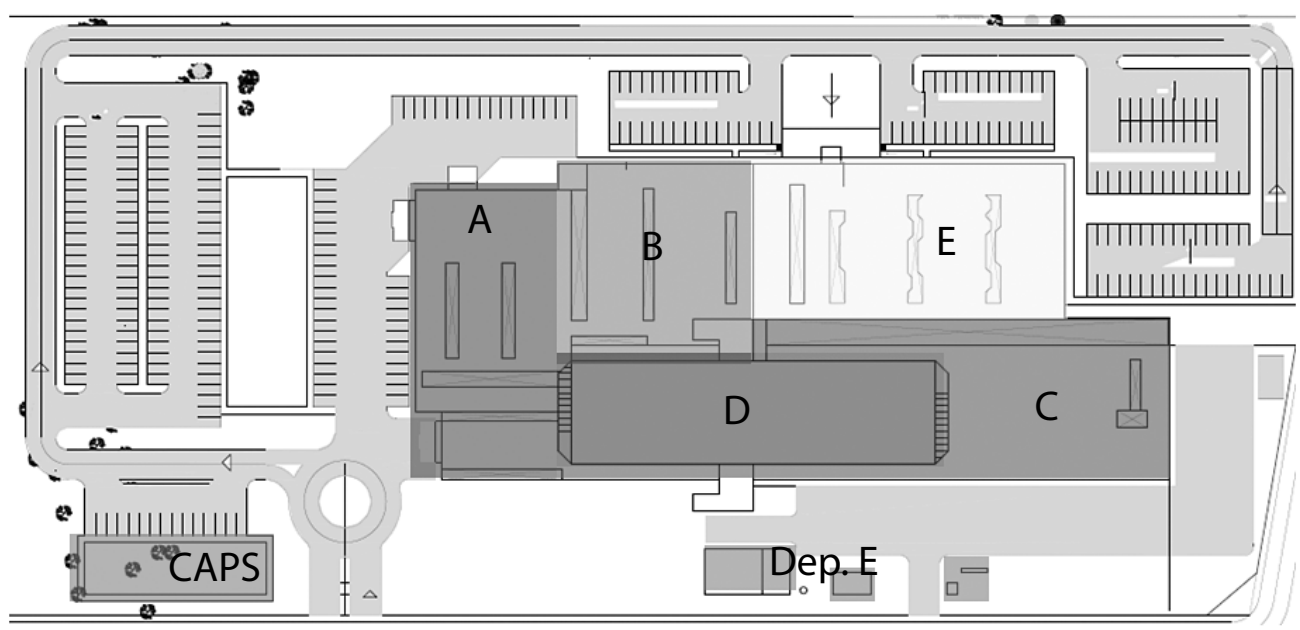

LEGENDA:

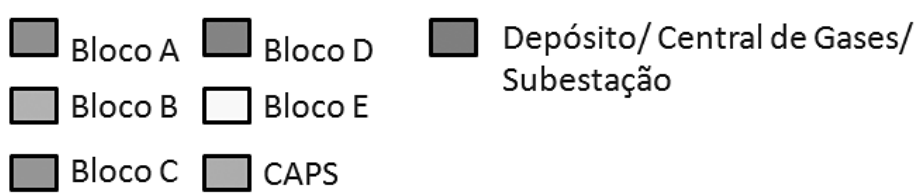

Fonte: Acervo pessoal

Tabela 1: Quadro de áreas segundo distribuições de funções do HRPa.

\begin{tabular}{|c|c|c|c|}
\hline COR & NÍVEL & DISCRIMINAÇÃO & ÁREA $\left(\mathrm{m}^{2}\right)$ \\
\hline & SUBSOLO & BLOCO D - RESERVATÓRIO INFERIOR E CASA DE MÁQUINAS & $1.857,15$ \\
\hline & SUBSOLO & BLOCO E - SERVIÇOS GERAIS & $1.694,30$ \\
\hline & TÉRREO & BLOCO A - EMERGÊNCIA, B. DE LEITE, ANAT. PATOLÓGICA, ORTOPEDIA & $1.913,50$ \\
\hline & TÉRREO & BLOCO B - LABORATÓRIO E RADIOLOGIA & $1.897,05$ \\
\hline & TÉRREO & BLOCO C - ADMINISTRAÇÃO & 974,80 \\
\hline & TÉRREO & BLOCO D - CME, C. CIRÚRGICO, C. OBSTETRÍCIO, UTI & $2.777,85$ \\
\hline & TÉRREO & BLOCOE - REFEITÓRIO & 180,50 \\
\hline & 19 PAVIMENTO & BLOCO C-AMBULATÓRIO & $2.070,25$ \\
\hline & 10 PAVIMENTO & BLOCO D - BLOCO TÉCNICO & $2.169,90$ \\
\hline & 20 PAVIMENTO & BLOCO D - INTERNAÇÃO, AUDITÓRIO E BIBLIOTECA & $2.140,65$ \\
\hline & 3ㅇ PAVIMENTO & BLOCO D - INTERNAÇÃO OBSTETRÍCIA, NEONATAL E PEDIATRIA & $2.239,45$ \\
\hline & 4ㅇ PAVIMENTO & BLOCO D - INTERNAÇÃO CIRURGIA GERAL E ORTOPÉDICA & $2.239,45$ \\
\hline & 5 PAVIMENTO & BLOCO D - CASA DE MÁQUINAS ELEVADORES E RESERVATÓRIO SUPERIOR & 190,70 \\
\hline \multicolumn{3}{|r|}{ ÁREA TOTAL: } & $22.345,85$ \\
\hline & TÉRREO & CAPS - Centro de Atenção Psicossocial & 430,30 \\
\hline \multicolumn{3}{|r|}{ ÁREA TOTAL GERAL: } & $22.775,85$ \\
\hline & SUBSOLO & BLOCO C - ÁREA REMANESCENTE & 532,25 \\
\hline & TÉRREO & DEP. DE INFLAMÁVEIS, GRUPO GERADOR, C. DE GASES, SUBESTAÇÂO & 257,67 \\
\hline
\end{tabular}

Fonte: Acervo pessoal

O terreno no qual está locado possui, aproximadamente, $46.000 \mathrm{~m}^{2}$ e tem considerável inclinação, implicando em uma planta com diferentes cotas de nível (Figura 08).
Figura 08: Foto panorâmica dos blocos B e E.

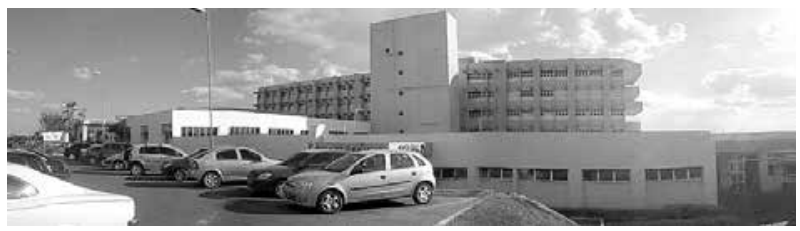

Fonte: Arquivo pessoal. 
O HRPa tem 6 acessos (Figura 09), sendo três deles voltados para os usuários (ambulatório e diagnóstico, emergência e ortopedia), um exclusivo para pacientes

Figura 09: Esquema de acessos ao HRPa - planta baixa, s/ escala. vindos de ambulância, acesso à parte administrativa, entrada de serviço e acesso ao bloco do CAPS.

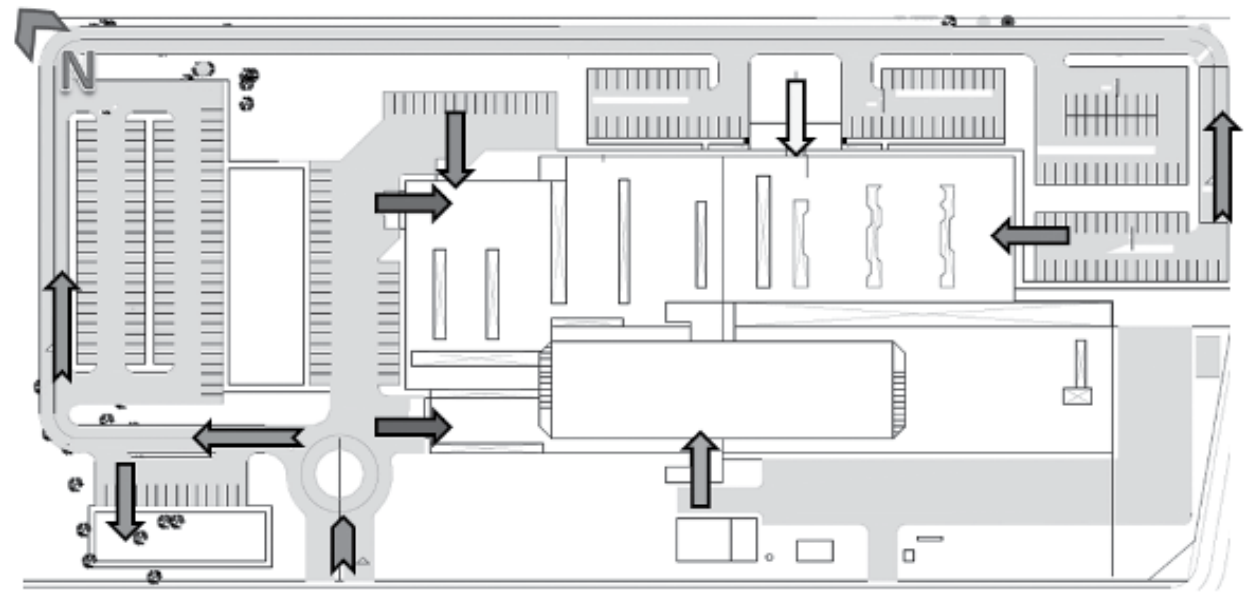

LEGENDA:

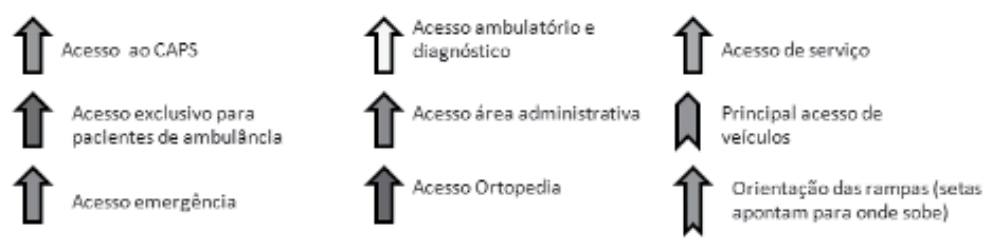

Fonte: Acervo pessoal

Para acessibilidade interna, o hospital dispõe de três elevadores, dois de serviço, um para pacientes, duas escadas de incêndio anexas a eles (Figura 10), uma rampa central (Figuras 11 e 12) e outra escada anexa a ela.

Figura 10: Esquema de acessos por elevadores e escadas de incêndio do HRPa - planta baixa, s/ escala.

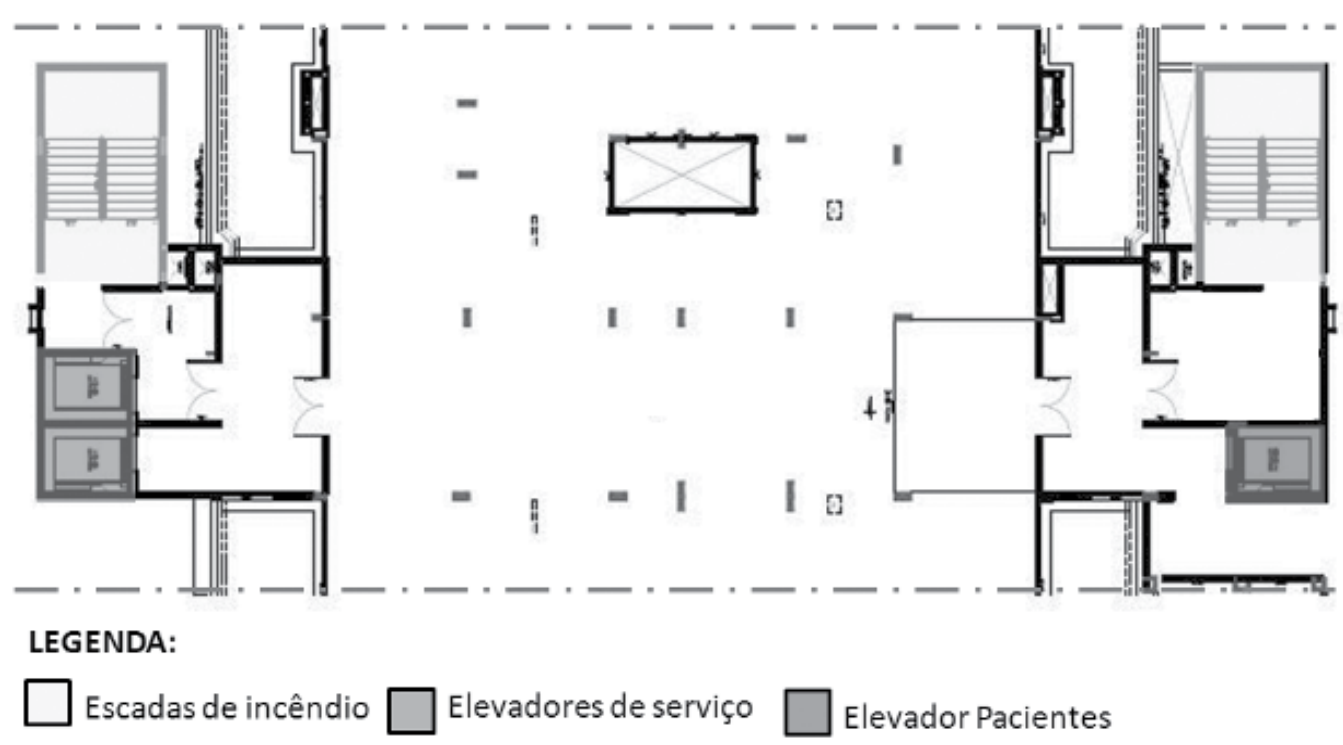

Fonte: Acervo pessoal 
Figura 11: Planta esquemática da rampa

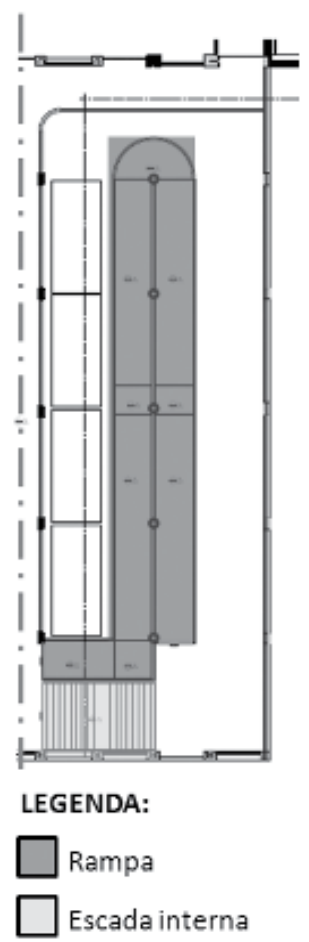

Fonte: Acervo pessoal

Figura 12: Rampa central do HRPa. Fonte:Arquivo escada anexa - planta baixa,s/ escala.

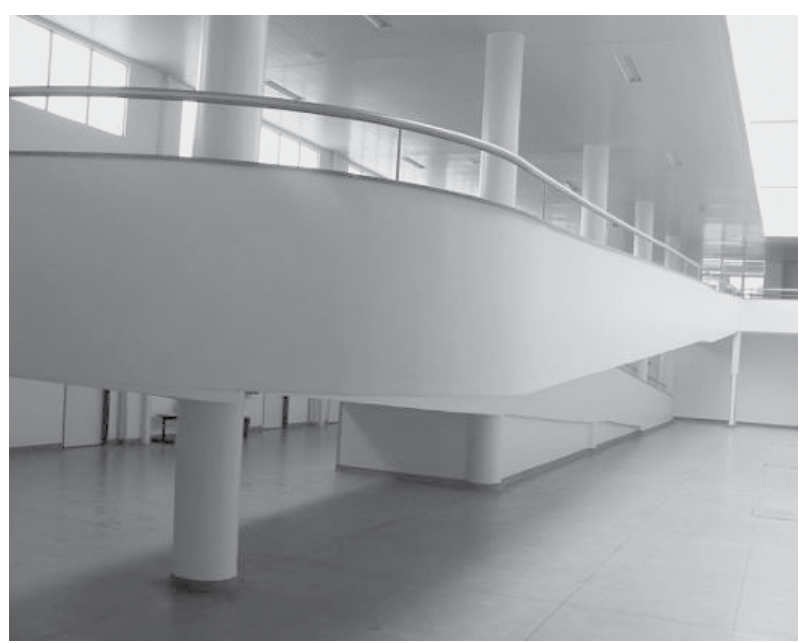

Fonte: Acervo pessoal

O projeto prevê, ainda, jardins internos (Figura 13) em toda extensão do hospital; entretanto, a maioria deles foi cimentado ou revestido de cerâmica (Figura 14).
Figura 13: Área em destaque corresponde ao jardim interno revestido em cerâmica - planta baixa, s/ escala

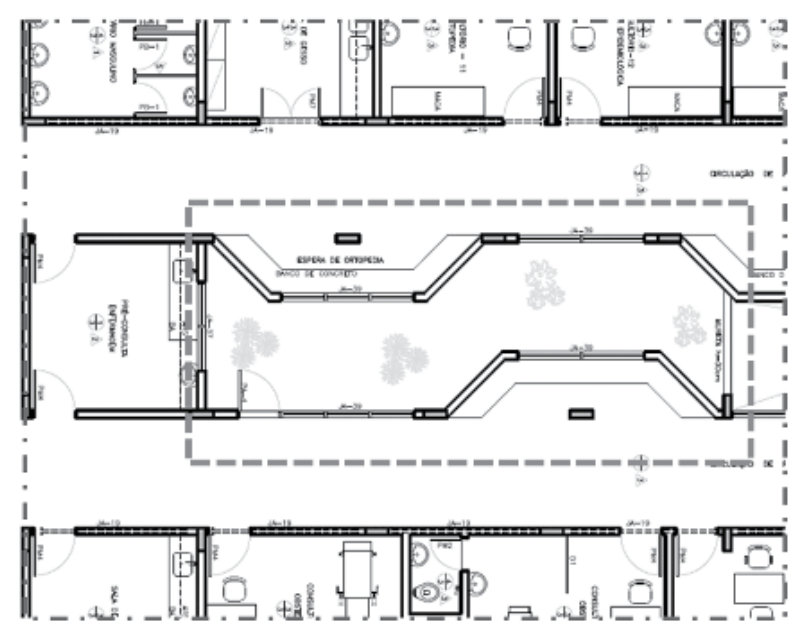

Fonte: Acervo pessoal

Figura 14: Área do jardim interno

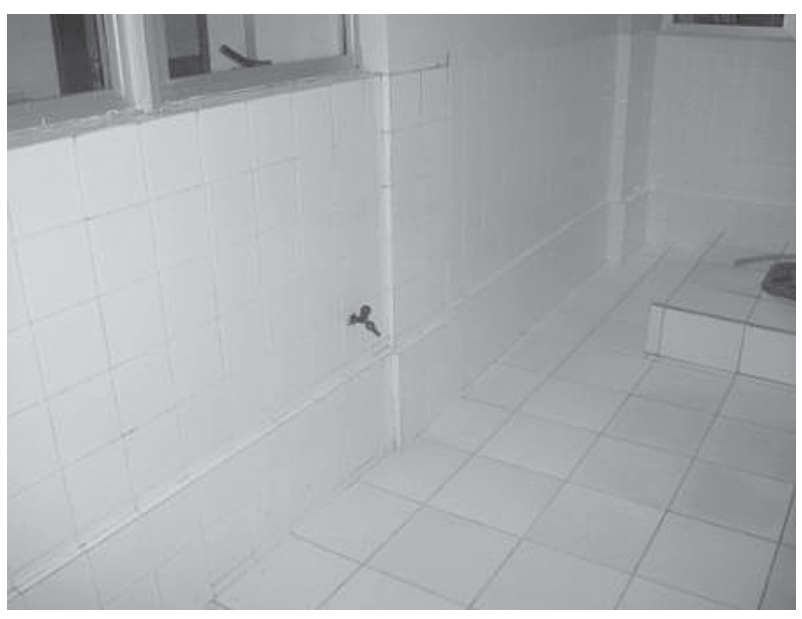

Fonte: Arquivo pessoal

Para análise mais detalhada, foram escolhidas quatro áreas das previstas na RDC 50/2002: Atendimento ambulatorial, Atendimento imediato, Internação e Apoio ao diagnóstico e terapia.

A Unidade de Atendimento Ambulatorial deve realizar registro de paciente e marcações de consultas, pequenos procedimentos médicos e odontológicos sob anestesia local, promover ações individuais ou coletivas de prevenção à saúde e executar e registrar procedimentos de enfermagem e médicos que não ultrapassem 24 horas.

O ambulatório do HRPa pode ser acessado pelo lado de fora por meio de uma entrada principal e outra secundária, localizada lateralmente. Internamente, podese acessar por meio da escada e da rampa central. 
Abrange uma área de aproximadamente $2071 \mathrm{~m}^{2}$, divididos em 50 salas, circulações de pacientes e de funcionários, banheiros, jardins internos, guarda-volumes, depósito de materiais de limpeza, expurgo e sala de espera (Figura 15).

Figura 15: Esquema da morfologia do Ambulatório - planta baixa, s/ escala.

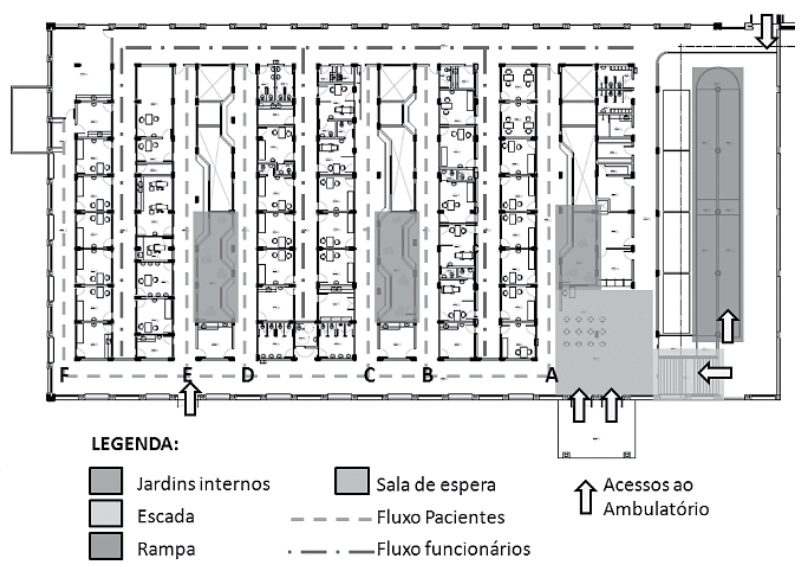

Fonte: Acervo pessoal

As salas estão dispostas umas ao lado das outras, formando corredores que se dividem de A a F, constituindo acessos para pacientes, e outros exclusivos para funcionários. Possui as especialidades de Cardiologia, Pequenas Cirurgias, Odontologia, Neurologia, Dermatologia, Geriatria, Urologia, Ginecologia, além de pré-consulta em enfermagem, sala de higienização, de chefia, de registro e ouvidoria, além de o corredor $\mathrm{F}$ ser exclusivo para vigilância epidemiológica.

Os jardins internos, que se localizam nas circulações para pacientes, foram projetados de tal maneira que as paredes que os limitam formam bancos para a espera dos usuários do EAS.

A Unidade de Atendimento Imediato, mais conhecida como emergência, deve, segundo a norma RDC 50/2002, proporcionar "atendimento a pacientes externos em situações de sofrimento, sem risco de vida (urgência) ou com risco de vida (emergência)".
A emergência tem três acessos externos principais: um destinado apenas a pacientes transportados por ambulância (Figura 16), um para pacientes pediátricos e outro para os demais, além de dois acessos secundários internos.

Figura 16: Esquema da emergência do HRPa - planta baixa, s/ escala.

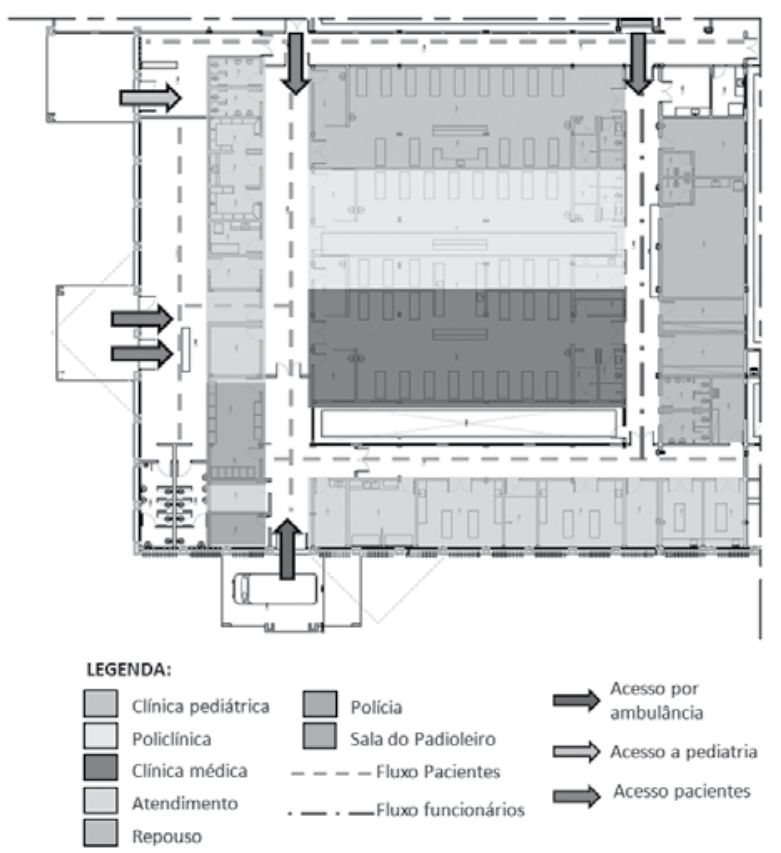

Fonte: Acervo pessoal

Possui aproximadamente $1533 \mathrm{~m}^{2}$, distribuídos em 42 leitos ao todo, área para atendimento dividida em algumas especialidades médicas específicas, como por exemplo: Ortopedia, Emergência de Traumas, Emergência Cardiológica, além de salas de nebulização, de injeção,de registro e de assistência social.

A Unidade de Internação assiste pacientes que necessitam de cuidados diretos por período superior a 24 horas. Destaca-se diante da composição volumétrica do HRPa por ser o único bloco com mais de 2 pavimentos, distinguindo-se como a área de monobloco vertical (Figura 17). 
Figura 17: Bloco de internação com caixa de escadas e elevadores

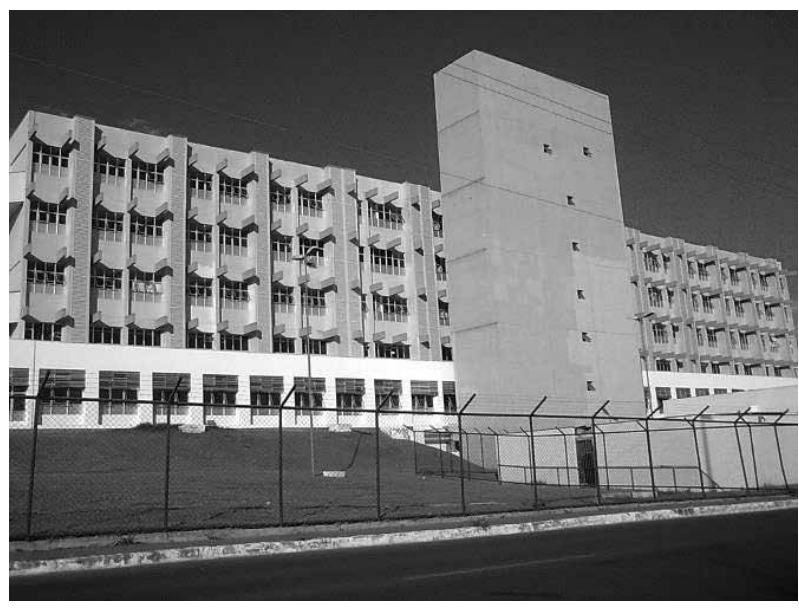

Fonte: Arquivo pessoal.
A internação tem ao todo uma área útil de, aproximadamente, $6621 \mathrm{~m}^{2}$, com 194 leitos divididos, de forma desigual, entre os três pavimentos destinados a pacientes. Pode-se acessá-la por meio de elevadores e da escada. Possui um corredor central que divide o bloco em duas alas interligando, transversalmente, os acessos de usuários e de serviços ao prédio. Em todos os pavimentos, os leitos serão divididos em enfermaria, que consistem em quatro leitos e dois banheiros em um só ambiente, e os quartos, com dois leitos e um sanitário em um único ambiente.

O $2^{\circ}$ pavimento de internação possui 32 leitos, sem restrição da utilização deles de acordo com o procedimento médico ou faixa etária, distribuídos em quartos e enfermarias, a parte de estudo como, por exemplo, a biblioteca, além de um auditório para mais de 100 lugares, uma sala dedicada à sindicância e 3 salas vazias (Figura 18).

Figura 18: Planta esquemática do $2^{\circ}$ pavimento de internação - s/ escala

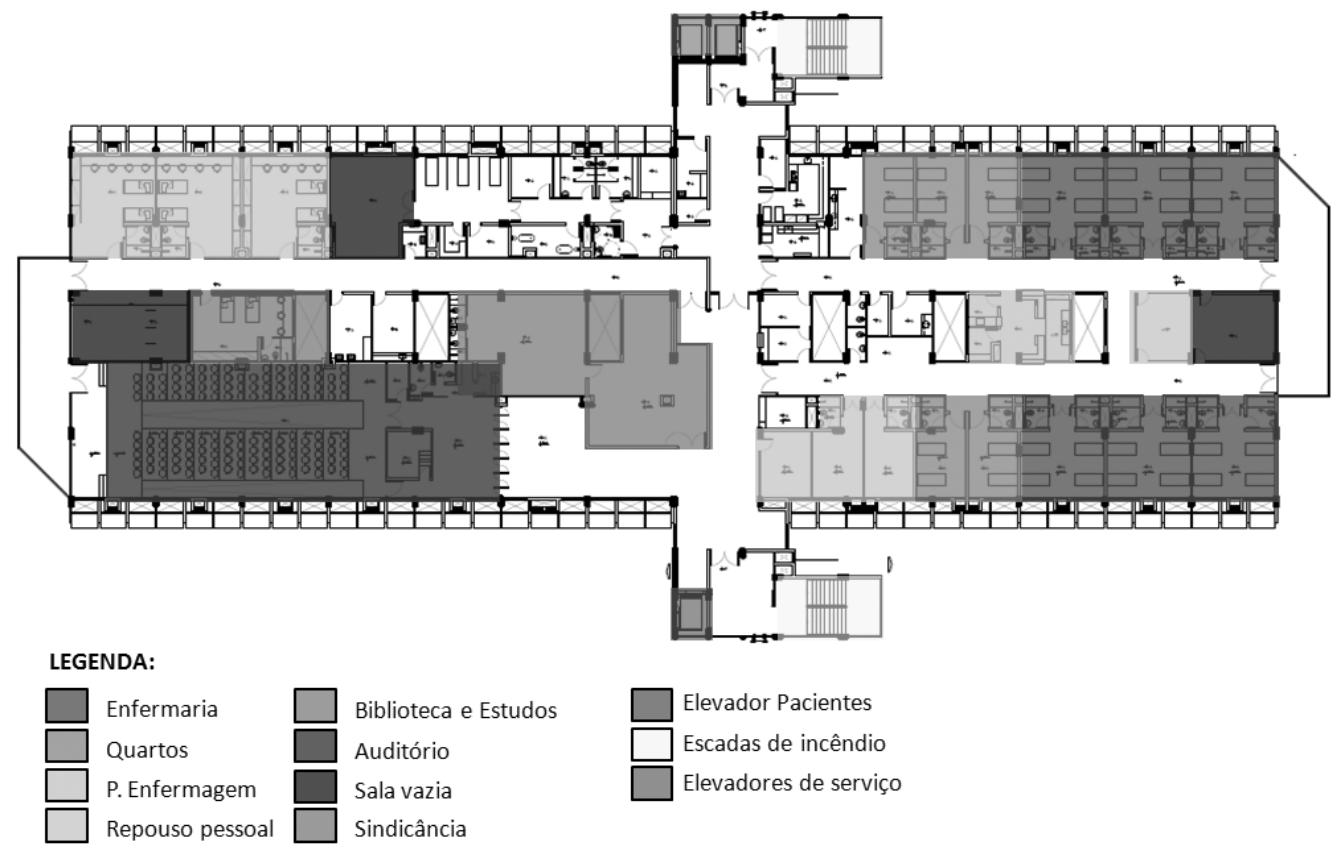

Fonte: Acervo pessoal

No $3^{\circ}$ pavimento de internação, há 70 leitos utilizados exclusivamente para pacientes obstétricos, pediátricos e neonatais. Eles se dividem em berçário ou dados intermediários e intensivos, enfermaria de 0 a 2 anos, quartos de 2 a 5 anos, de 5 a 7 anos, quartos e enfermarias para as pacientes da obstetrícia (Figura 19). 
Figura 19: Planta esquemática do $3^{\circ}$ pavimento de internação - s/ escala

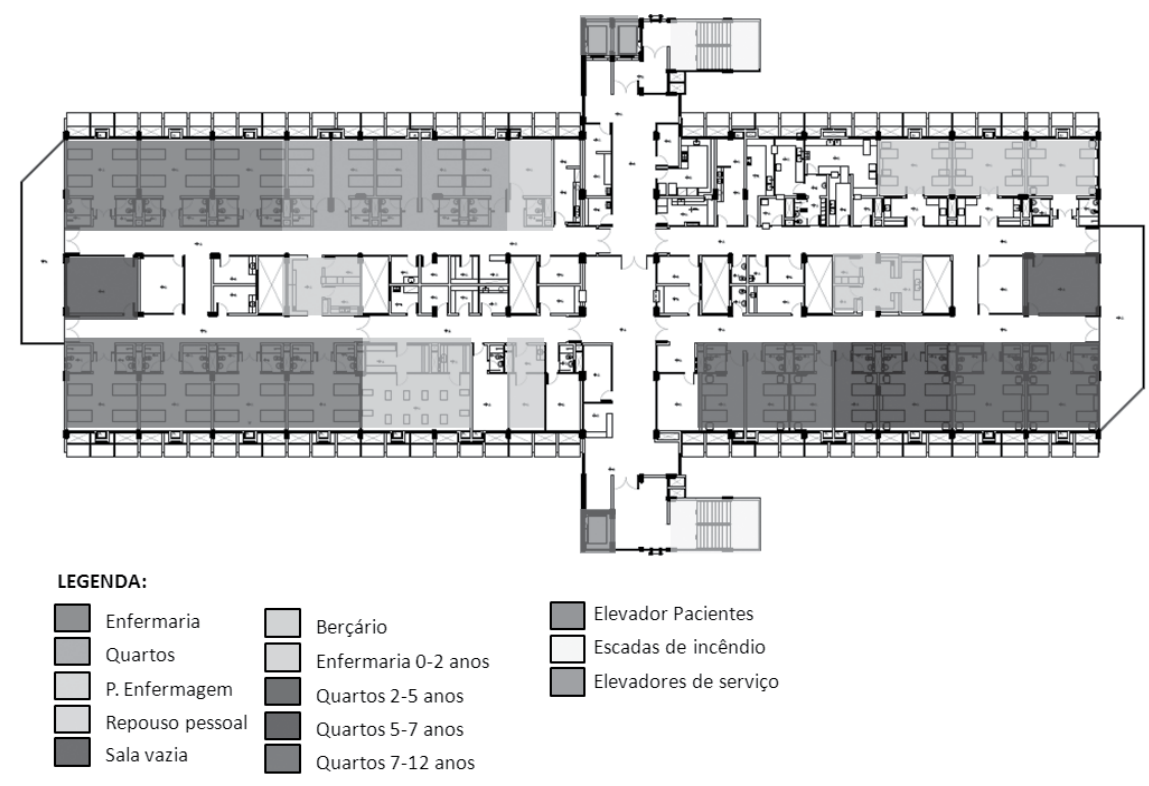

Fonte: Acervo pessoal

O $4^{\circ}$ pavimento do Bloco de Internação separa as duas partes formadas pelo corredor central em alas A e B, sendo a primeira utilizada para pacientes submetidos a procedimentos de ortopedia e a segunda, para pacientes de cirurgia geral (Figura 20).

Figura 20: Planta esquemática do $4^{\circ}$ pavimento de internação - s/ escala

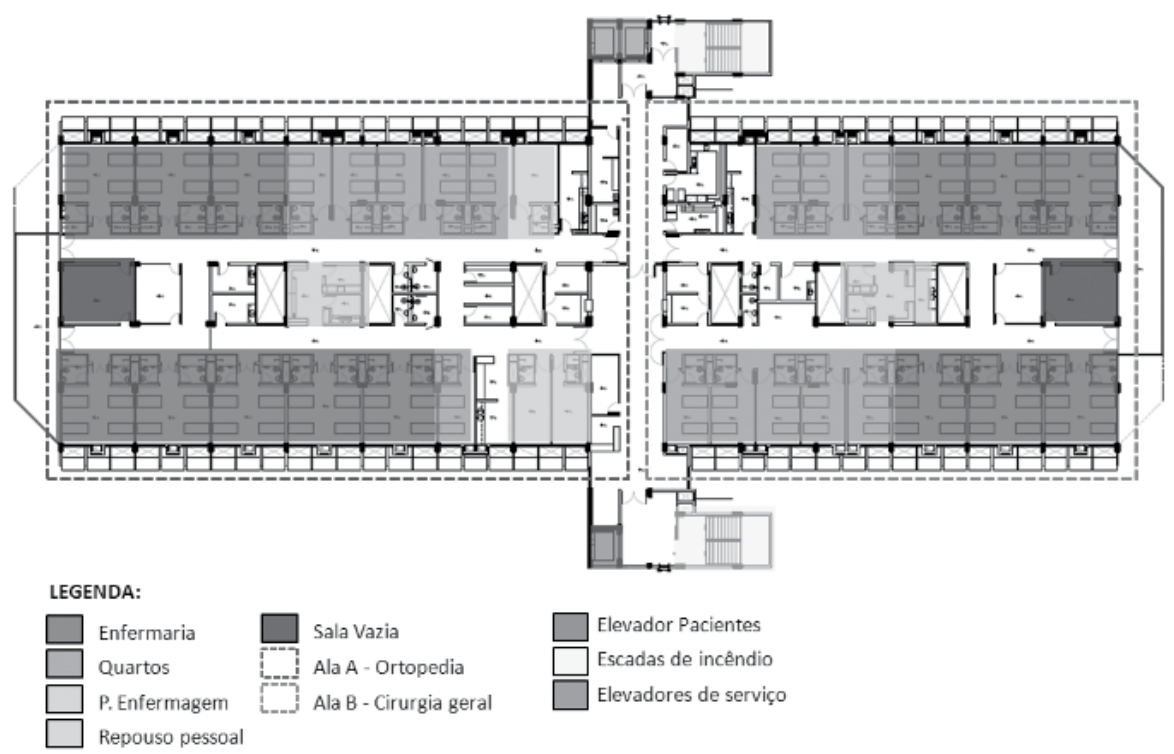

Fonte: Acervo pessoal

Por fim, a área de Apoio ao Diagnóstico e Terapia tem como função, segundo a RDC 50/2002, atender "a pacientes internos e externos em ações de apoio direto ao reconhecimento e recuperação do estado da saúde (contato direto)".
Nessa área, não há junção de todas as especialidades que abrangem um só local, mas há junção de funções semelhantes em locais próximos, como por exemplo, os Centros Cirúrgico, Obstetrício e UTI, que estão próximos uns aos outros. 
As áreas de Necropsia e Guarda-cadáver, Ortopedia e Banco de Leiite se encontram próximos uns aos outros, com acessos independentes tanto interna quanto externamente (Figura 21).

Figura 21: Planta esquemática das áreas de ortopedia, necropsia e banco de leite - s/ escala.

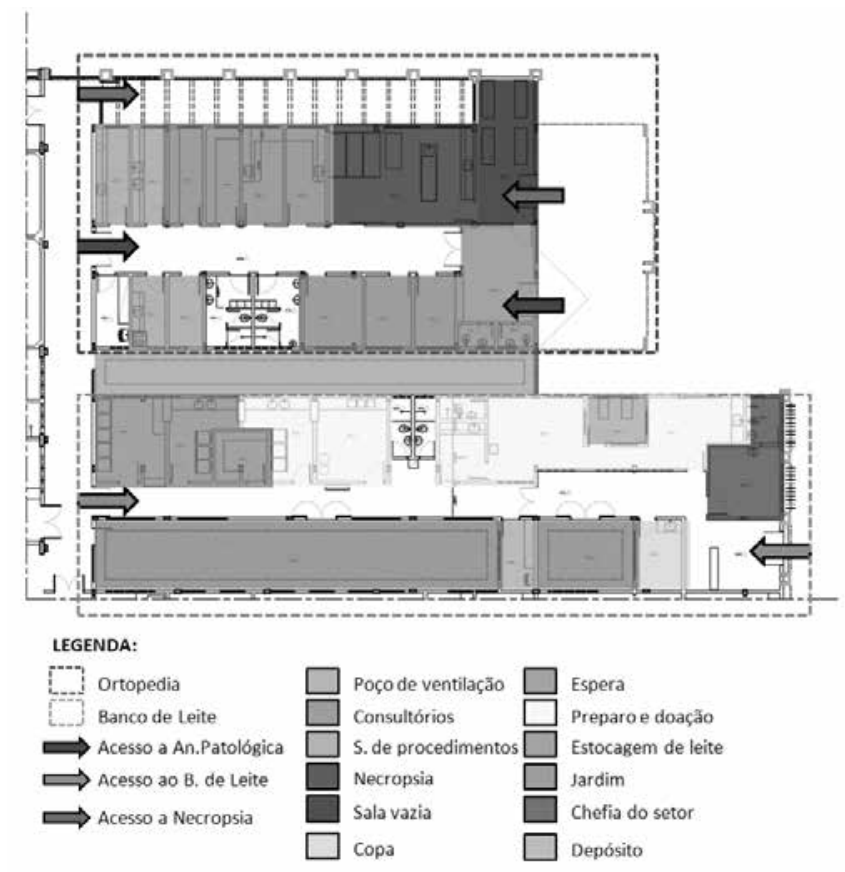

Fonte: Acervo pessoal

A primeira possui acesso isolado interno, na porção lateral, utilizado para transportar cadáveres para a necropsia ou para guardá-los, sem que haja contato deles com os pacientes em atendimento na Ortopedia; e, externamente, há também acesso exclusivo para uma sala vazia com o intuito de facilitar o transporte do corpo para outro local.

$\mathrm{Na}$ área de Ortopedia, os pacientes que a acessam externamente ficam em uma sala de espera que, além de local para sentar, possui uma recepção e dois banheiros. Internamente, acessa-se diretamente o corredor principal da ala. Nele, há quatro consultórios para atendimento, duas salas de procedimento, sendo uma delas exclusiva- mente para gesso, e dois banheiros para usuários e funcionários.

A terceira (Banco de Leite) possui acesso externo dedicado às doadoras, que entram em uma sala de recepção e se dirigem diretamente à área de preparo e doação. A porção mais próxima ao acesso interno é a de estocagem, portanto, facilita, dessa maneira, a distribuição do leite doado.

O Bloco Cirúrgico, localizado no térreo do bloco D, possui aproximadamente $2778 \mathrm{~m}^{2}$ e abriga o Centro Cirúrgico (CC), Centro Obstétrico (CO), UTI, Centro de Material e Esterilização (CME) e a Farmácia (Figura 22). O acesso a esse bloco só pode ser feito por dentro do hospital. 
Figura 22: Planta esquemática do bloco cirúrgico - s/ escala.

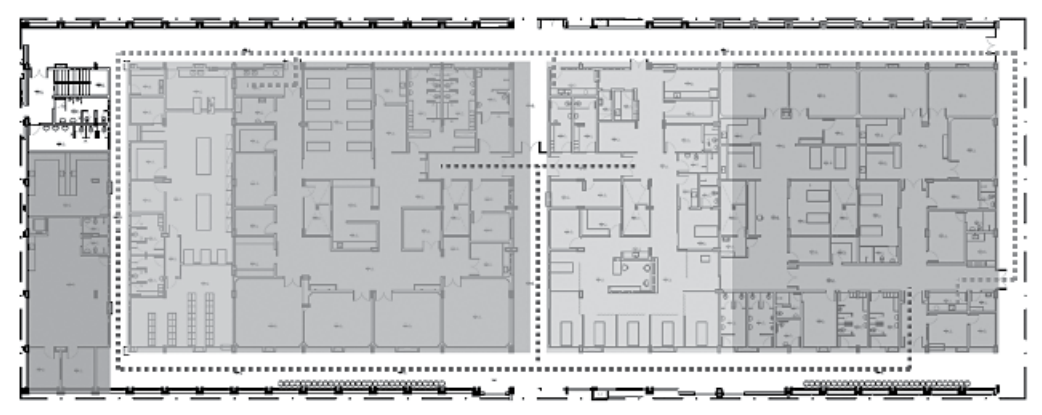

LEGENDA:

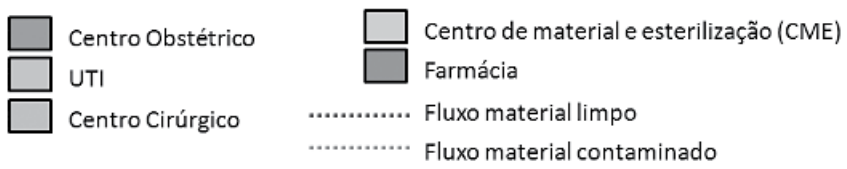

Fonte: Acervo pessoal

Há três corredores que delimitam o Bloco Cirúrgico: dois longitudinais e um transversal. Um dos logitudinais tem acesso restrito, sendo utilizado para circulação apenas de funcionários e material contaminado, este último proveniente do CC, CO e da UTI, sendo que a coleta do CO é feita pelo corredor transversal.
A última área a ser estudada na Unidade de Apoio ao Diagnóstico e Terapia é a destinada aos laboratórios, que analisam material biológico e de exames (Figura 23). Encontra-se próxima à rampa que leva ao primeiro pavimento, onde há a Unidade de Atendimento Ambulatorial.

Figura 23: Planta esquemática da área de laboratórios do HRPa - s/ escala.

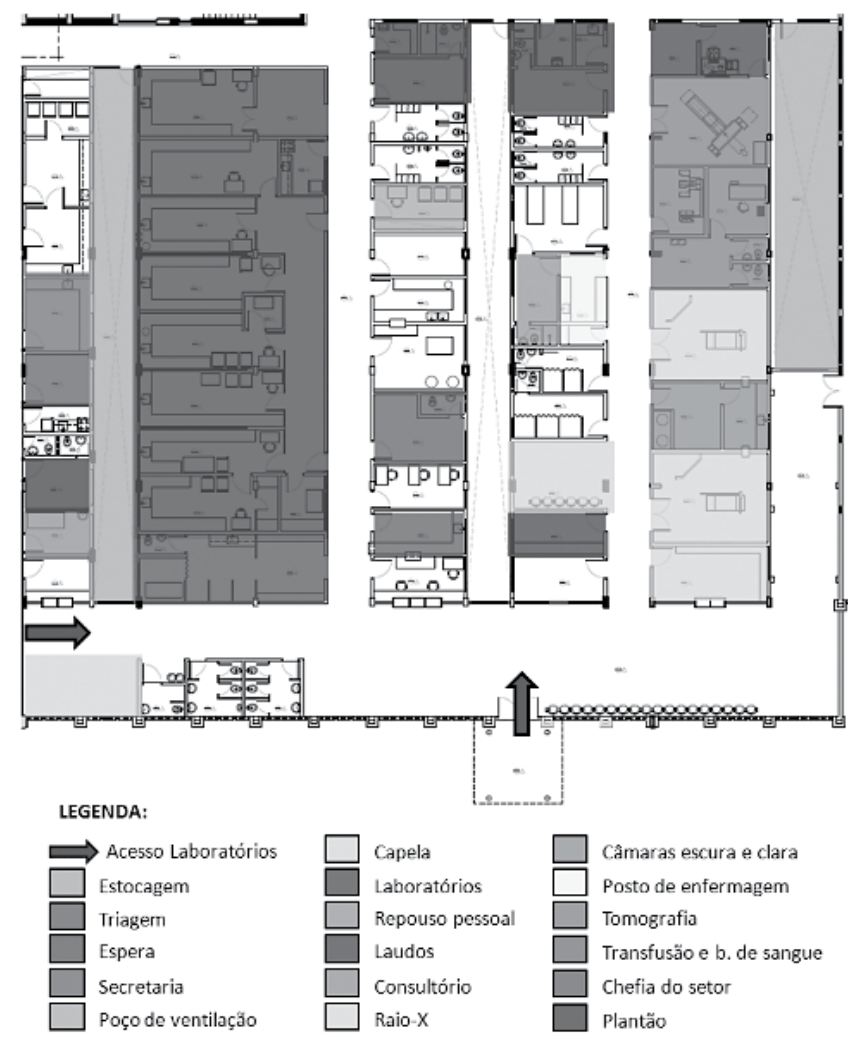


Possui dois acessos, um externo, feito por meio de rampas para quem se encontra no nível do primeiro pavimento, e um interno. Nessa unidade, também há a utilização de poços de ventilação para aproveitamento da ventilação natural.

\section{Resultados e discussão}

$\mathrm{O}$ arquiteto, ao desenvolver um projeto, independentemente da função a ser atribuída a esse espaço, deve preocupar-se não somente em atender rigorosamente o programa que lhe foi dado, mas deve também resgatar princípios como o bom uso de recursos naturais do sítio e a humanização dos ambientes, que há tempos têm sido coadjuvantes.

Analisando o sítio em que o HRPa se encontra, segundo princípios de regime de ventos e insolação (Figura 24), pode-se dizer que houve um bom estudo preliminar quanto a esse item.

Figura 24: Esquema da análise das condicionantes ambientais do sítio do $\mathrm{HRPa}$ - s/ escala.

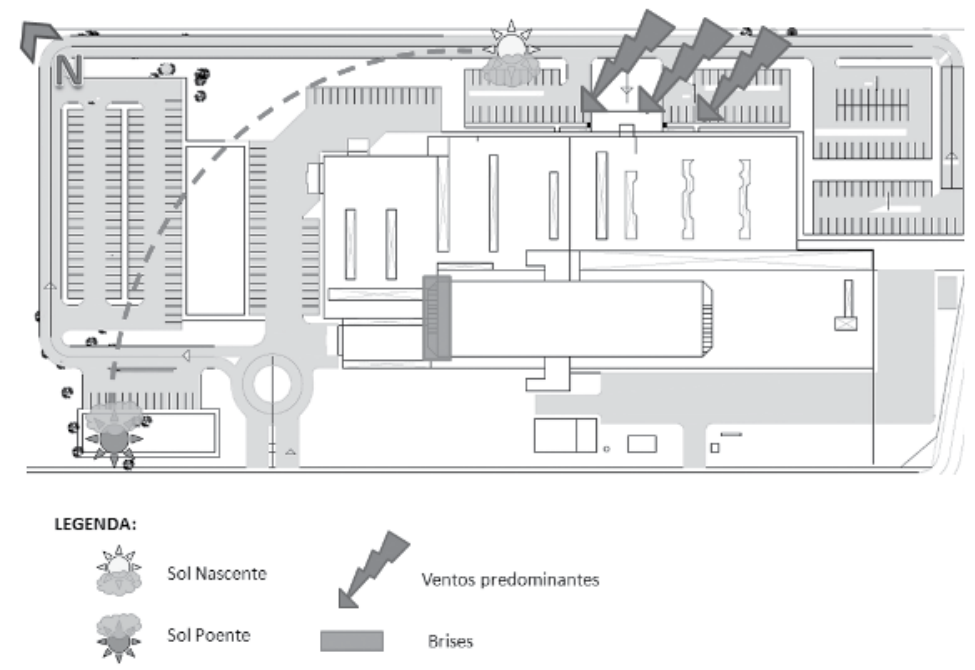

Fonte: Acervo pessoal

Os locais mais críticos de insolação são os que estão orientados na porção oeste. No HRPa, pode-se perceber que a menor extensão da edificação é voltada para esse ponto. Locais de permanência rápida, como atendimento imediato, orienta-se para oeste. $\mathrm{Na}$ Unidade de Internação, há uma parcela do bloco que receberá tamanha intensidade solar, utiliza-se da estratégia dos brises, que consistem em um dispositivo que impede que parte ou que toda a radiação seja bloqueada para dentro do edifício.

Na porção leste, onde há insolação matinal de baixa intensidade e predominância de ventos, acumula-se a maior parte das funções do HRPa: Unidade Ambulatorial, Unidade de Laboratórios e Raios-X e uma grande área da Unidade de Internação.

Acima da rampa central, foi colocada abertura zenital, que permite que toda área que ela abrange seja iluminada naturalmente durante o dia, sem que haja neces- sidade de se utilizarem lâmpadas, minimizando o gasto em energia elétrica (Figura 25).

Figura 25: Rampa central com detalhe para iluminação zenital.

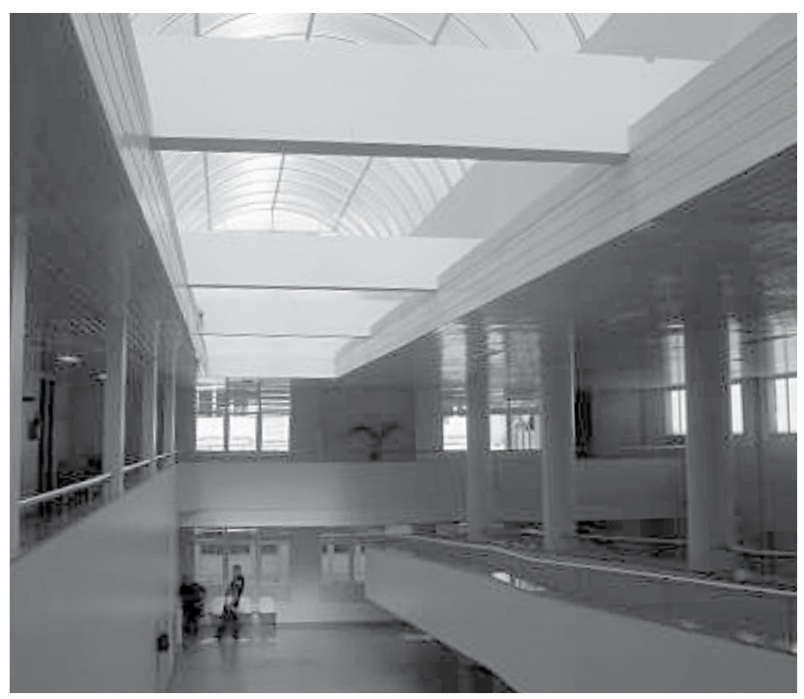

Fonte: Arquivo pessoal 
Foram também previstos neste projeto jardins internos, para que, além do aproveitamento da iluminação natural e dos ventos, haja também humanização dos espaços devido à presença de vegetação e ao aumento da umidade interna, essencial para o clima de Brasília.

Para otimização do uso de recursos naturais, aplicaram-se elementos vazados, os cobogós, que permitem a livre passagem de ventos através da edificação (Figura 26).

Figura 26: Detalhe de emprego de cobogós no HRPa

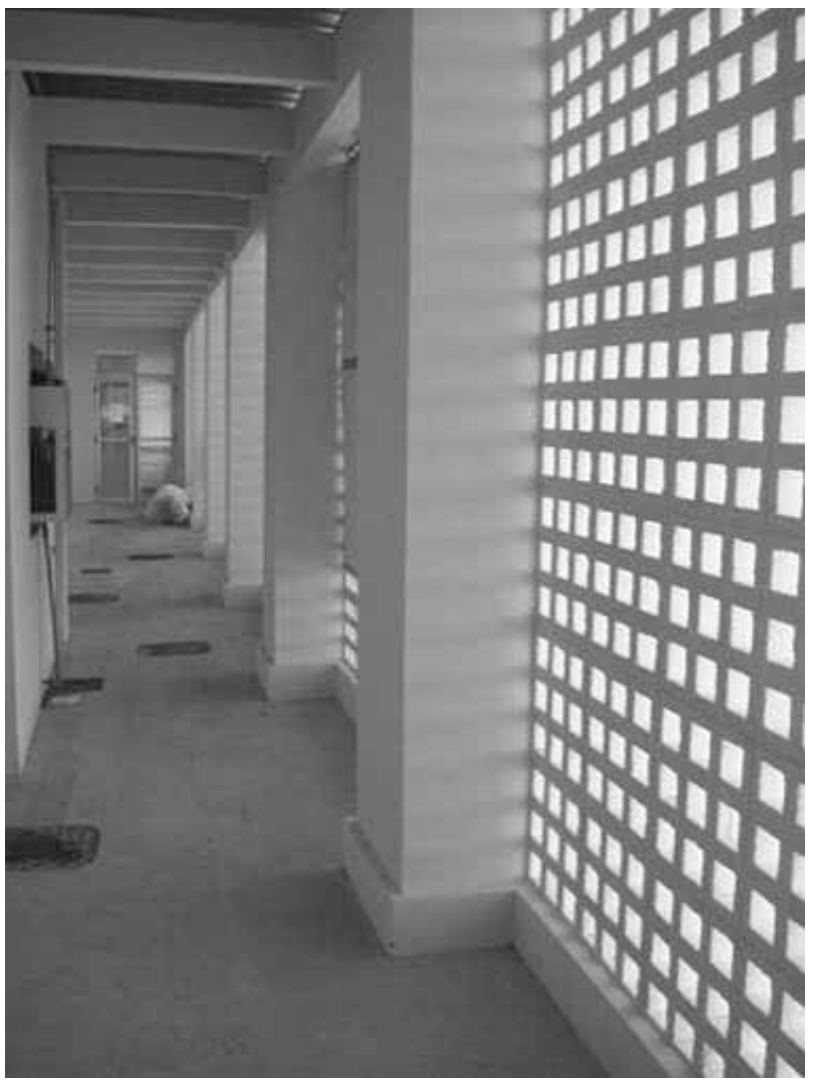

Fonte: Arquivo pessoal.

A acessibilidade em um EAS é essencial. O HRPa possui, internamente, rampa central com piso antiderrapante, corrimão e largura adequada, anexa a uma escada, três elevadores e duas escadas de incêndio.

Os corredores estão bem dimensionados e possuem bate-maca, proteções que são instaladas nas paredes e evitam riscos e arranhões causados por objetos como camas hospitalares, macas e cadeiras, com altura adequada, servindo também como corrimão, atendendo às exigências da norma RDC 50/2002 (Figura 27).

Figura 27: Detalhe do corredor do HRPa

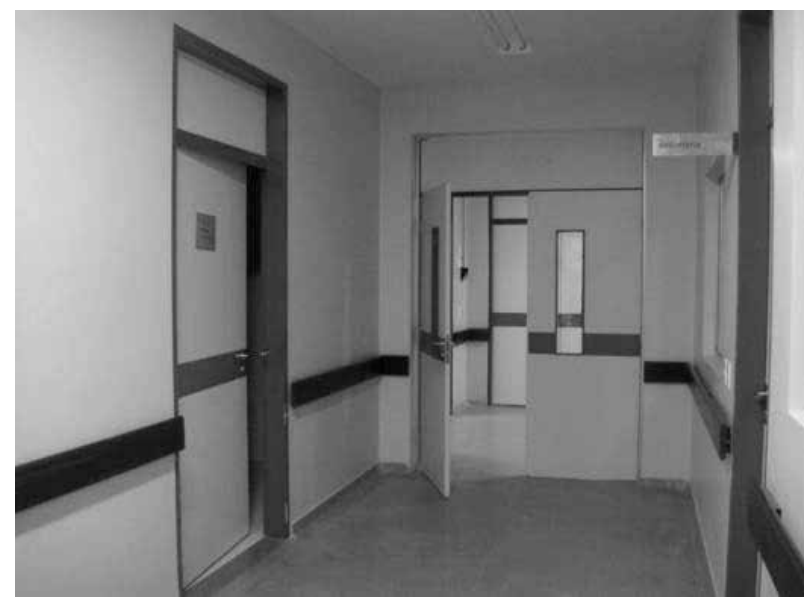

Fonte: Arquivo pessoal.

Entretanto, nos banheiros dos quartos e enfermarias da Unidade de Internação não há barras metálicas para auxiliar os pacientes que estão debilitados e necessitam de apoio ao tomar banho ou usar o banheiro. Apenas os banheiros especificados para portadores de necessidades especiais possuem essas barras.

Há um aspecto muito interessante no HRPa: a troca de funções de certos ambientes em áreas para repouso e depósito. Na emergência, perderam-se dois leitos ao converter salas de atendimento em repouso de pessoal. $\mathrm{Na}$ internação, perderam-se oito leitos. No laboratório, perdeu-se uma sala de diluição e no banco de leite, a área dedicada à amamentação de recém-nascidos transformou-se em depósito e o local que receberia coleta de leite materno externo converteu-se em copa.

Outro exemplo de mudanças de função pode-se encontrar no Centro Obstétrico. O projeto original prevê uma secretaria, com chefia anexa na parte mais externa, e expurgo e DML próximos ao corredor adjacente (Figura 28). 
Figura 28: Planta do projeto original de parte do $\mathrm{CO}$ - planta baixa, s/ escala

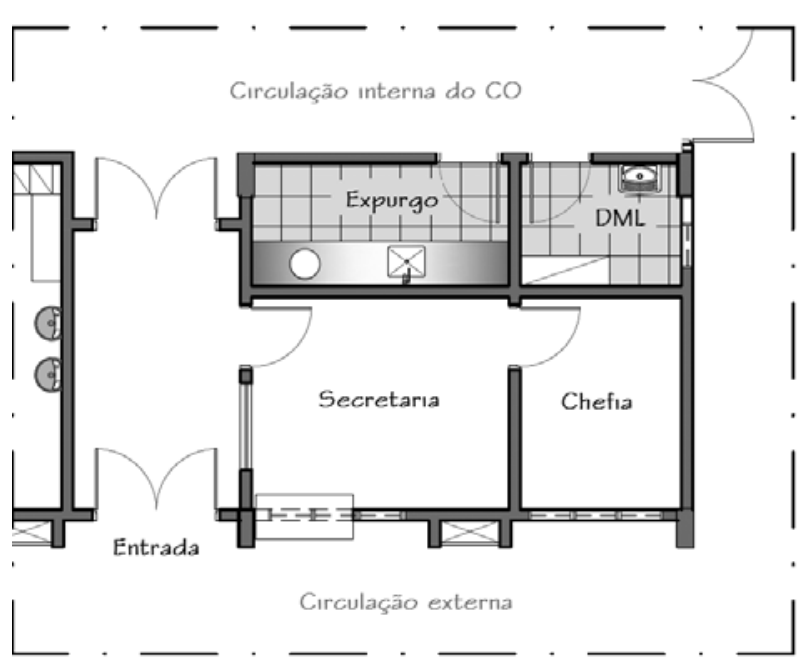

Fonte: Acervo pessoal

No entanto, houve uma tentativa frustrada de criar uma área para triagem (Figura 29) com dois consultórios, uma área de atendimento separada apenas por uma divisória da área de consulta e uma sala de exames.

Figura 29: Planta de Layout de como se encontra parte do CO atualmente $-\mathrm{s} /$ escala

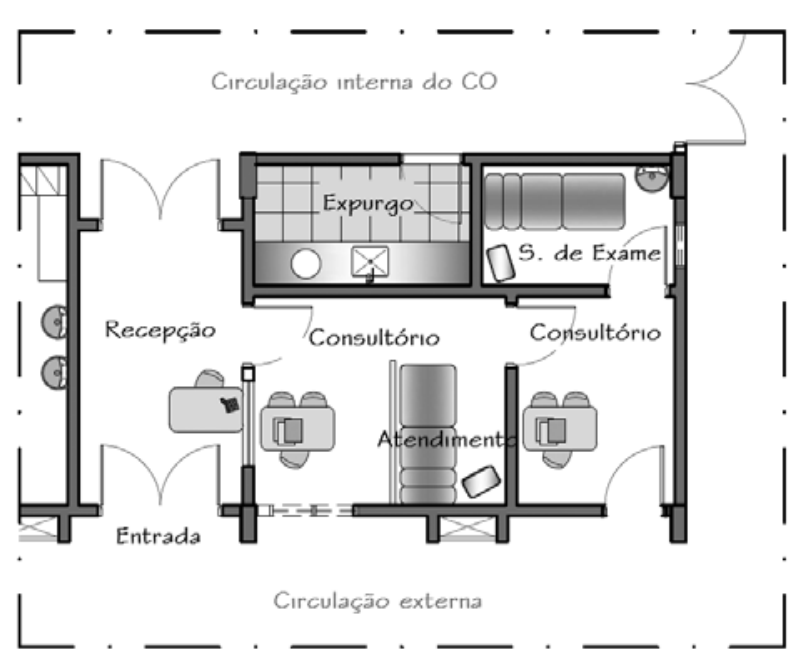

Fonte: Acervo pessoal
Foi improvisada a recepção em um local que era apenas para circulação. Apesar do consultório à direita ter duas portas de acesso, apenas uma é usada, que é a compartilhada com o outro consultório. Tais mudanças feitas não tiveram acompanhamento de um profissional da área.

A UTI tem um bom funcionamento, e o manejamento do espaço é adequado à função que ela desempenha. Mas há algumas soluções simples que otimizam o funcionamento da unidade. Apesar de a Unidade de Tratamento Intensivo necessitar de isolamento do restante dos ambientes e ser fechada, não significa que não possa haver janelas lacradas, verdadeiros painéis de vidro, que proporcionem ao paciente interagir com o exterior, de preferência voltados para jardins, com abundância de luz natural, para estimulá-lo, auxiliando, dessa forma, na cura de sua enfermidade.

O uso de cores em diversos ambientes do HRPa é recorrente e resgata o princípio de humanidade da arquitetura, tornando o ambiente hospitalar, que por natureza é hostil, em um local mais agradável e auxiliando na cura dos pacientes (Figura 30). 
Figura 30: Exemplos de locais no HRPa onde há utilização de diferentes cores.
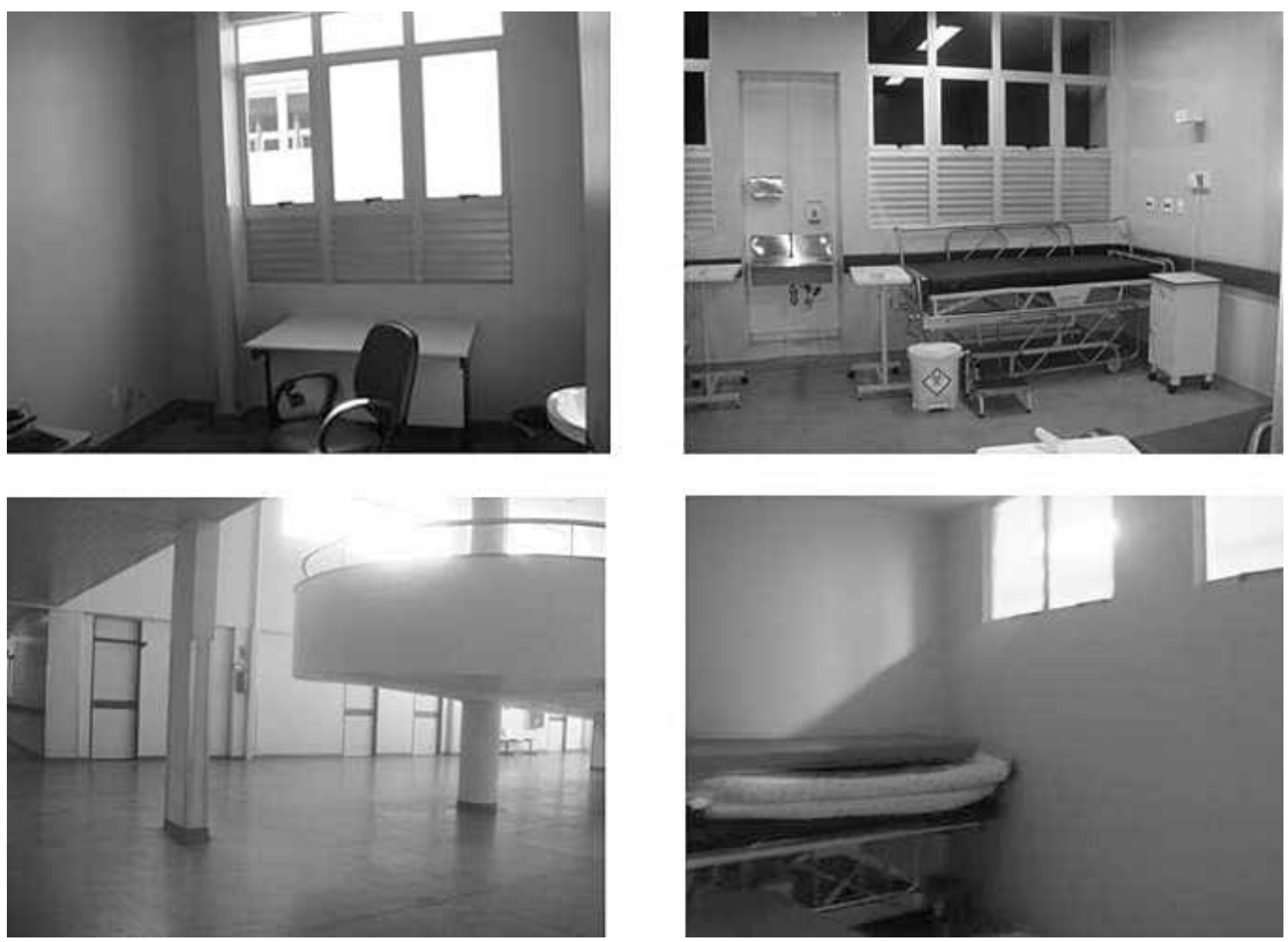

Fonte: Arquivo pessoal.

\section{Considerações finais}

O estudo preliminar de um ambiente hospitalar, quando bem executado, permite ao arquiteto prever problemas executivos, pós-ocupacional ou até facilitar posteriores reformas; resgata o conceito humanitário do espaço, adequa o programa e as funções aos avanços da medicina e ao cotidiano do EAS; planeja a melhor maneira de manejar espaços para que eles se encaixem, simultaneamente, ao programa e ao local em que estão inseridos.

O HRPa tem um projeto que se destaca dentre os hospitais da Secretaria de Saúde pela sua solução arquitetônica que leva em consideração aspectos ambientais, do sítio e do entorno, relembra questões humanitárias devido à internalização do exterior, alcançada por meio de jardins internos, abundância do uso da luz natural e utilização de cores. Entretanto, há diversas modificações do projeto original feitas sem auxilio de um profissional, acarretando resultado negativo para os seus usuários, desencadeando dificuldades no pós-ocupacional que o estudo desenvolvido para projeto original não pode prever.

Apesar de idealista, a arquitetura não é a única responsável pelo bom funcionamento do local que planeja. $\mathrm{O}$ arquiteto preocupa-se em adequar o programa estabelecido às condicionantes e aos obstáculos que um projeto tem. Portanto, em um hospital, por exemplo, de nada adianta que haja uma excelente resolução espacial se não há administração eficiente, manutenção apropriada ou até mesmo seguimento do projeto arquitetônico. Enfim, a arquitetura tem um grande peso no bom funcionamento de um EAS sim, mas deve estar aliada aos administradores dele, para que haja sincronia entre o que é necessário e o resultado esperado. 


\section{Referências}

ANVISA. RDC 50/2002: estabelecimentos assistenciais de saúde. Brasília: Ministério da Saúde, 2002.

ARAUJO, E. P. Avaliação crítica de ambientes em estabelecimentos assistenciais de saúde. 2008. 254 páginas. Tese (Doutorado) - Escola Nacional de Saúde Pública, Fundação Oswaldo Cruz, Rio de Janeiro, 2008.

ASSOCIAÇÃO BRASILEIRA DE NORMAS TÉCNICAS. NBR 7.256/2004: tratamento de ar em estabelecimentos assistenciais de saúde, materiais de acabamento aplicados na edificação. Rio de Janeiro: ABNT, 2004.

ASSOCIAÇÃO BRASILEIRA DE NORMAS TÉCNICAS. NBR 9.050/2004: acessibilidade. Rio de Janeiro: ABNT, 2004.

BOCCANERA, N. B. A utilização das cores no ambiente de internação hospitalar. 2007. 95 páginas. Dissertação (Mestrado) - Universidade Federal de Goiás, Goiânia, 2007.

CAMPOS, E. S. História e evolução dos hospitais. Rio de Janeiro: Ministério da Saúde, 1944.

FIORENTINI, D. M. F. Arquitetura na prevenção da infecção hospitalar. Brasília: Ministério da Saúde, 1995.
FOUCAULT, M. Microfísica do poder. Rio de Janeiro: Graal, 1979.

KARMAN, J. B. Manutenção incorporada à arquitetura hospitalar. Brasília: Ministério da Saúde, 1995.

LIMEIRA, F. M. Arquitetura e integralidade em saúde: uma análise do sistema normativo para projetos de estabelecimentos assistenciais de saúde. 2006. 177 páginas. Dissertação (Mestrado) - Universidade de Brasília, Brasília, 2006.

SAMPAIO, A. V. C. Arquitetura hospitalar: projetos ambientalmente sustentáveis, conforto e qualidade. 2006. 402 páginas. Tese (Doutorado) - Universidade de São Paulo, São Paulo, 2006.

SANTOS, M.; BURSZTYN, I. Saúde e arquitetura: caminhos para a humanização dos ambientes hospitalares. Rio de Janeiro: Senac, 2004.

TOLEDO, L. C. Feitos para curar: arquitetura hospitalar e processo projetual no Brasil. 2002. 175 páginas. Dissertação (Mestrado) - Universidade Federal do Rio de Janeiro, Rio de Janeiro, 2002.

WESTPHAL, E. A. Linguagem da arquitetura hospitalar de João Filgueiras Lima. 2007. 122 páginas. Dissertação (Mestrado) - Universidade Federal do Rio Grande do Sul, Porto Alegre, 2007. 
Para publicar na revista Universitas: Arquitetura e Comunicação Social, acesse 0 endereço eletrônico www.publicacoesacademicas.uniceub.br. Observe as normas de publicação, para facilitar e agilizar o trabalho de edição. 